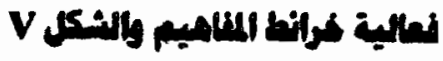 \\ فل خلفز ألح تحطيل الطلب لهادة المنطة
}

\section{بالمرحلة الثانوية}

الاكتى / سامى معمد على النطايرى

كية التربية - جامعة الزتازيق

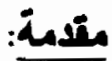

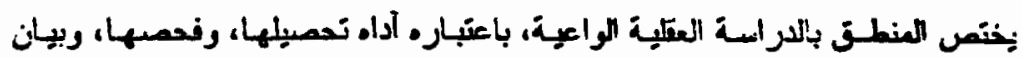

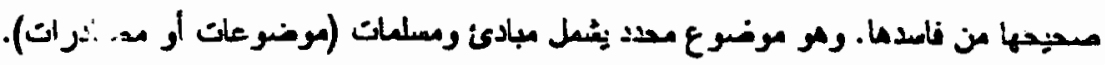

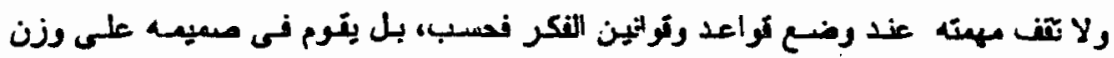

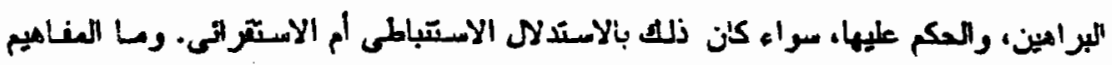
والعبانين المنطتية إلا تعبير عن عليات منطفية تكاد تكون واحدة.

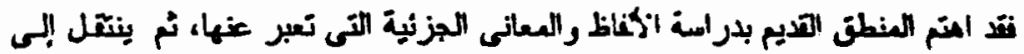

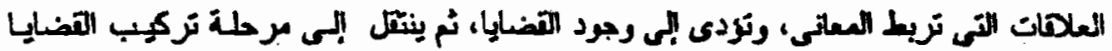

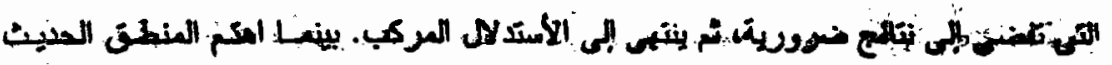

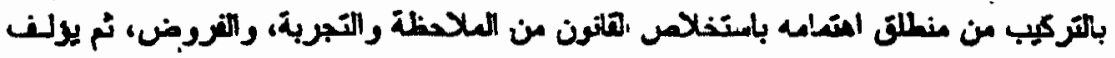

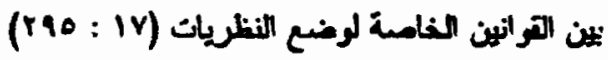

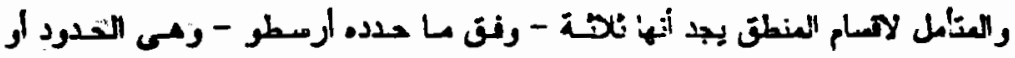

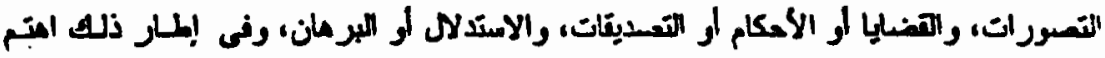

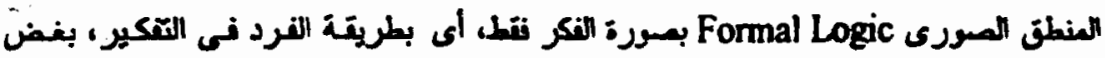

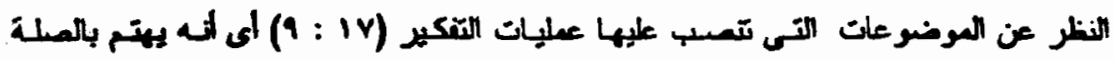

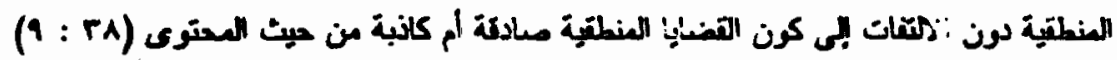

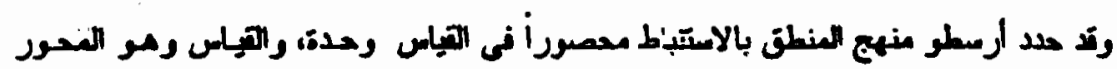

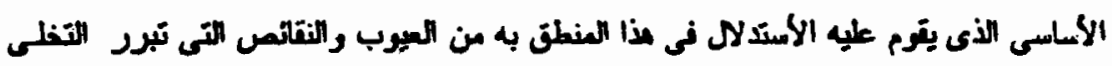

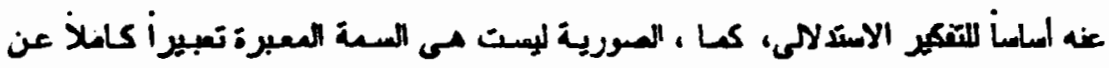

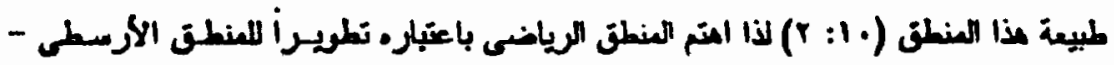

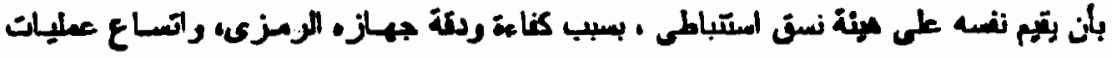

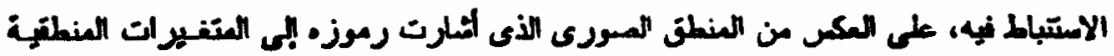




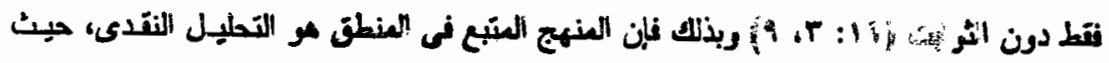

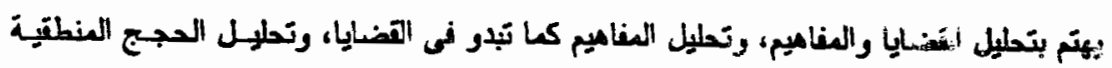

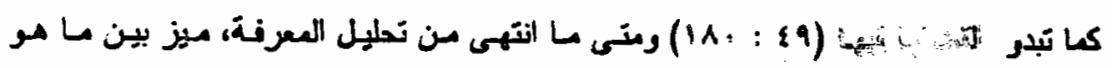

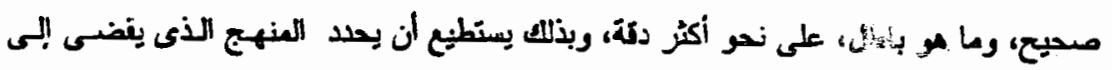

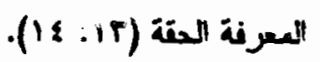

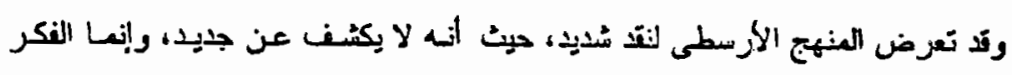

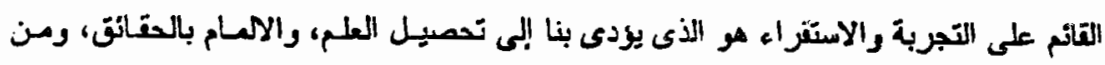

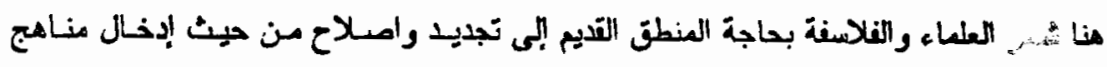

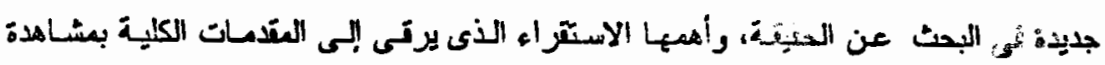

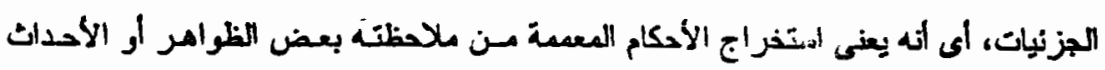

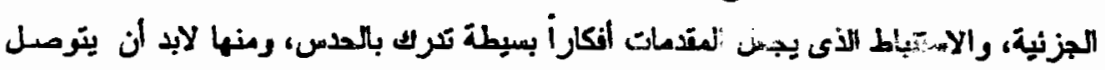

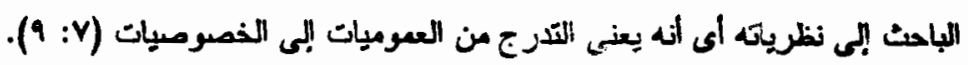

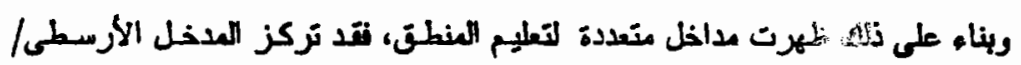

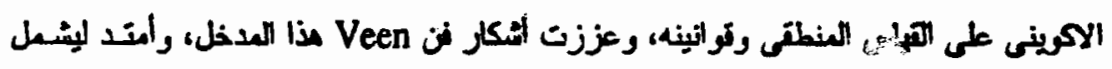

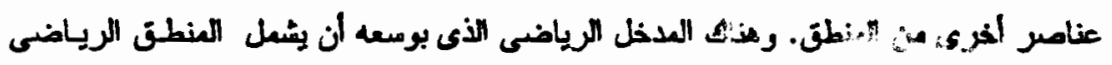

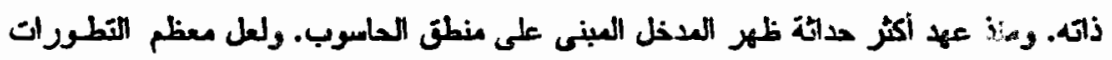

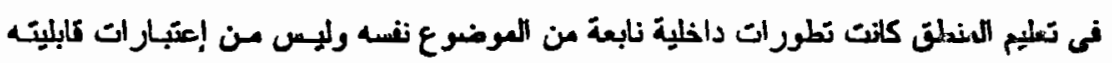

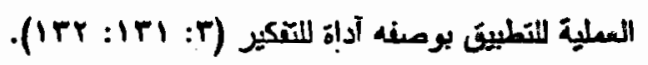

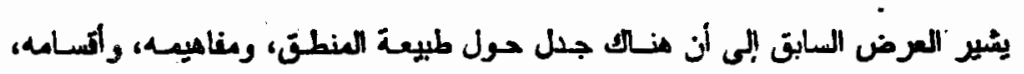

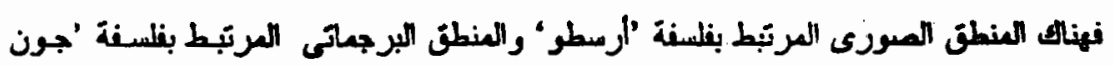

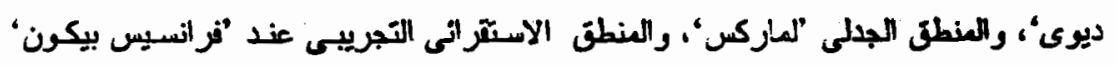

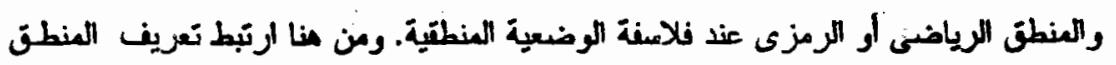

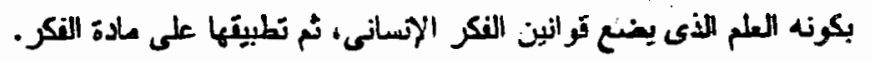

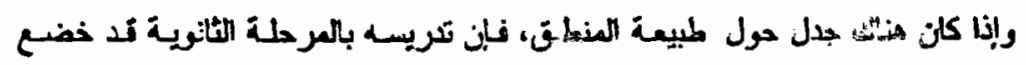

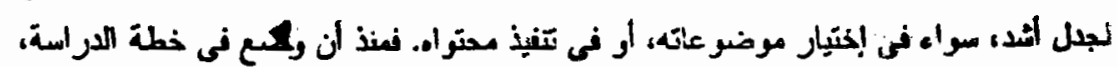

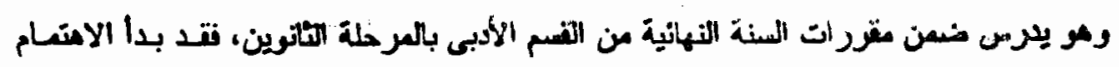




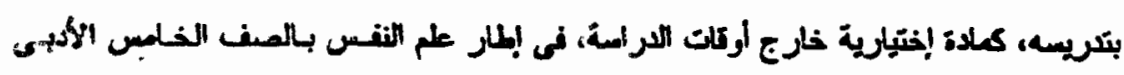

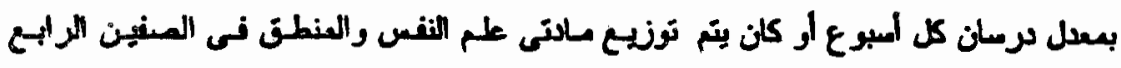

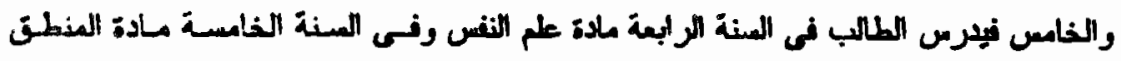

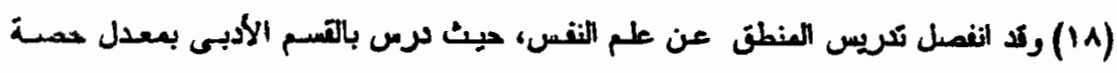

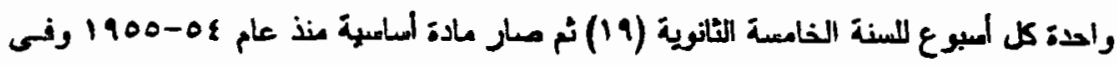

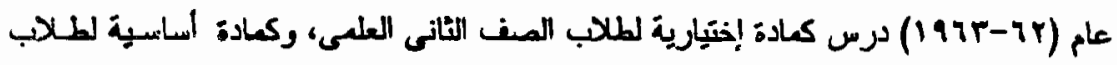

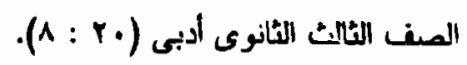

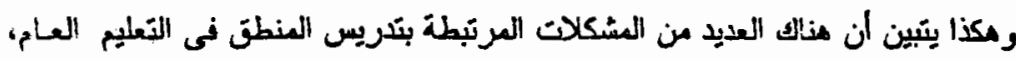

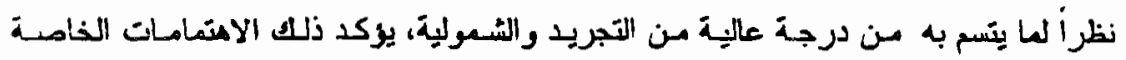

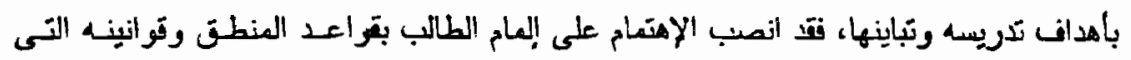

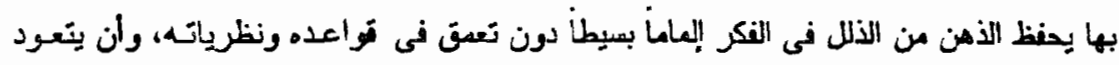

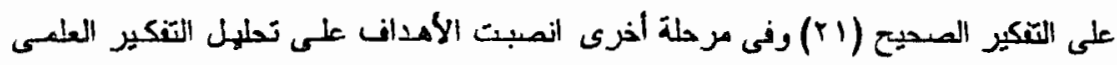

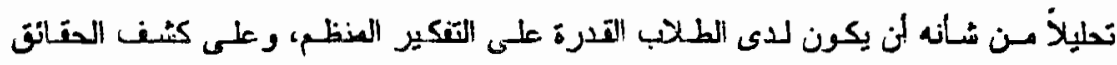

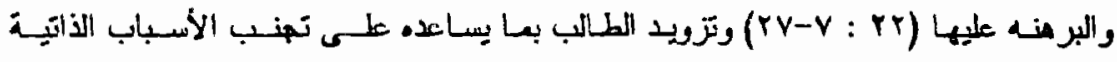

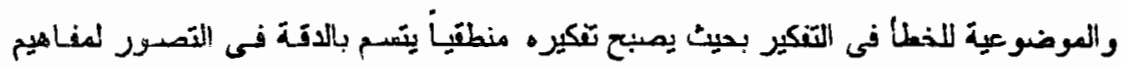

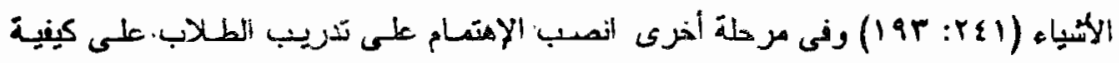

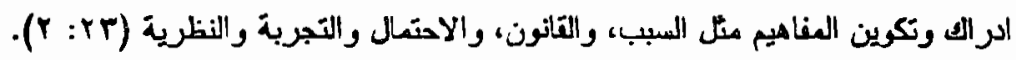

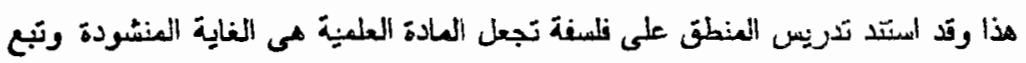

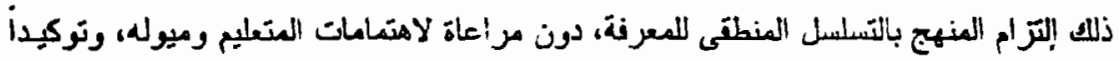

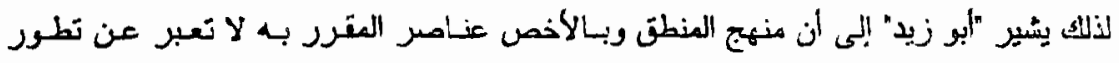

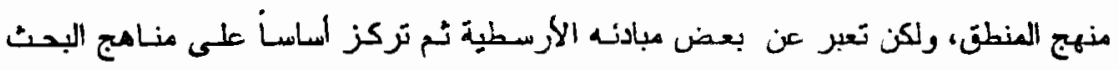

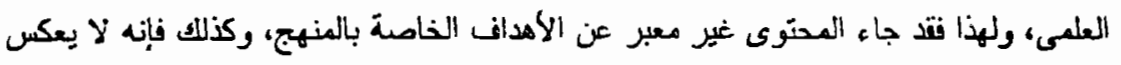

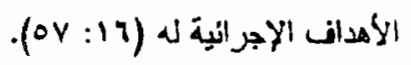

وبالرغم من تعدد العفاهيم المنطتية، وارتباط أهداف تدريس العنطن بها، إلا أن المادة

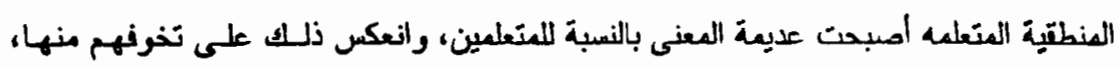

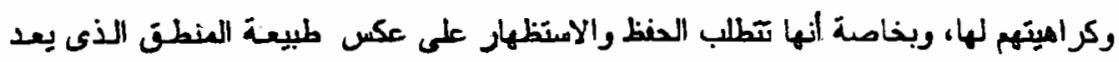

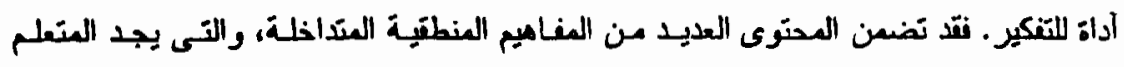




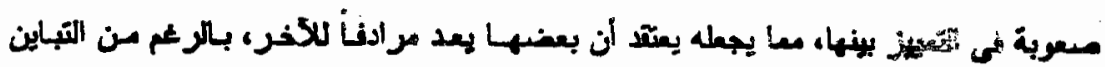

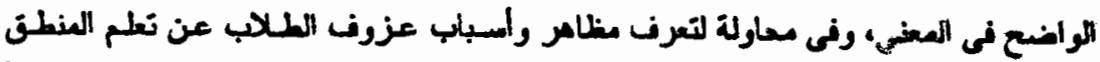

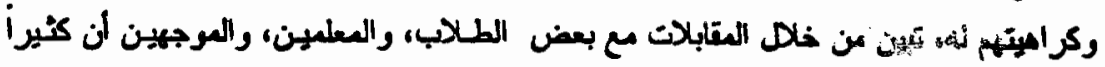

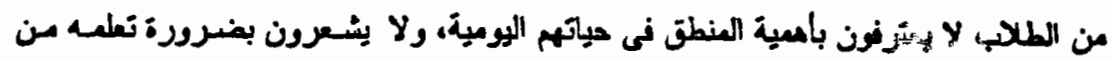

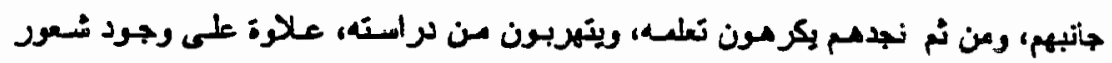

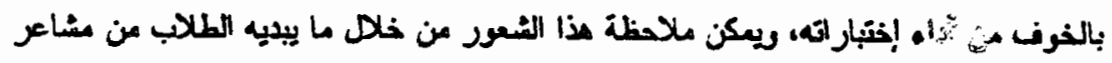

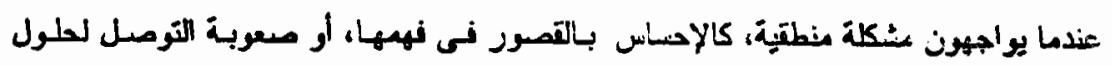

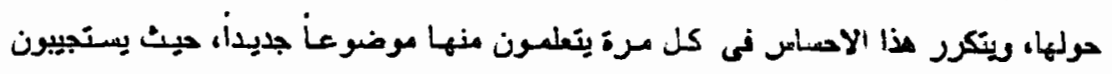

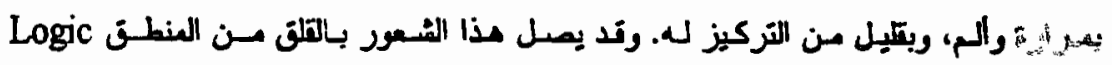
Arxiety أو بتكت التحمبل فى المنطق. وتد يرجع ذلك إلى الأسباب التالهة:-

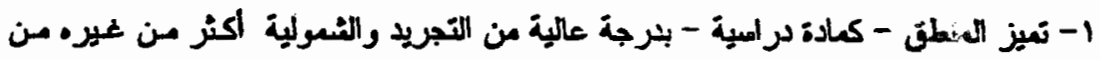

العواد التلهفية.

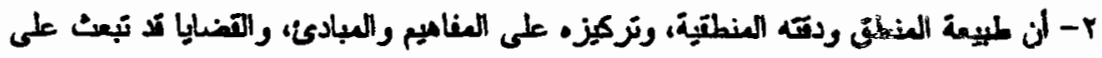

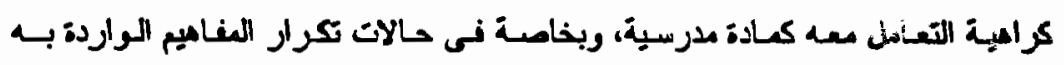

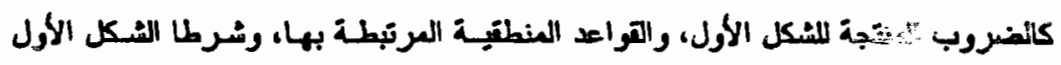

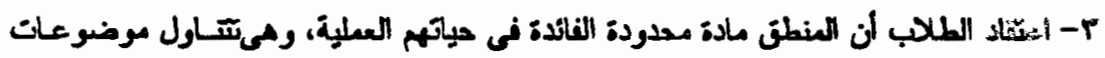

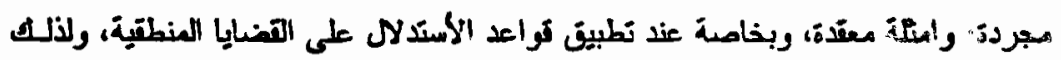

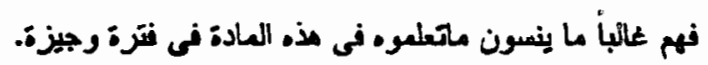

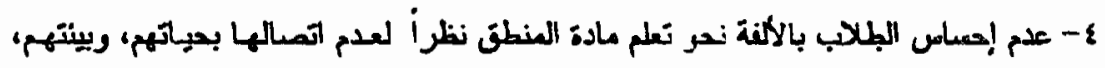

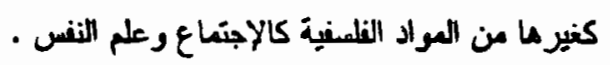

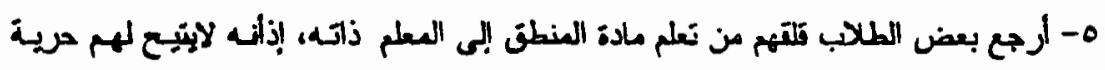

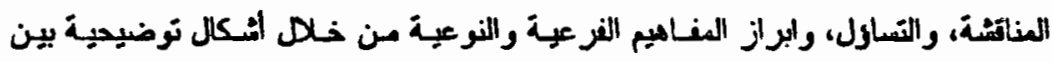

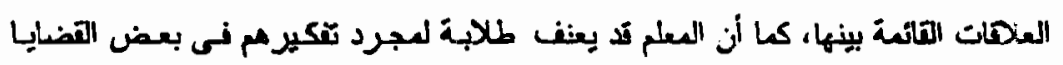

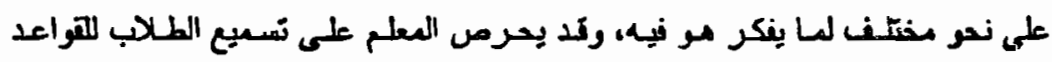

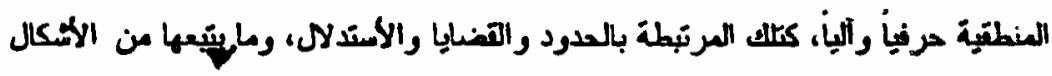

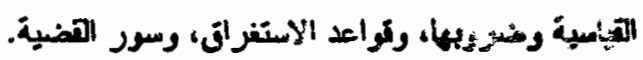

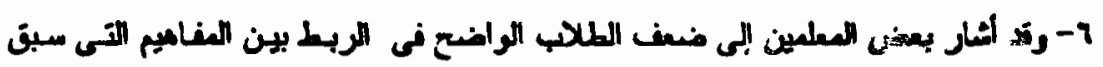

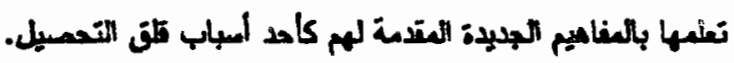




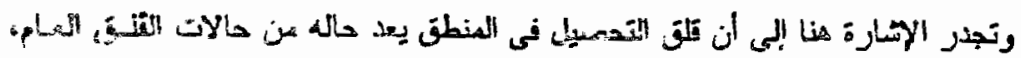

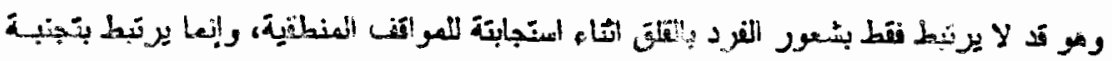

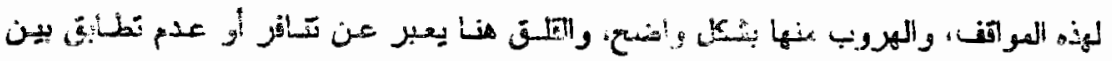

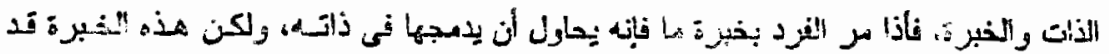

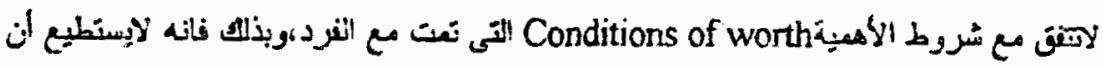

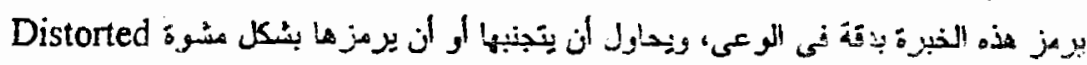
(IVT: ic)

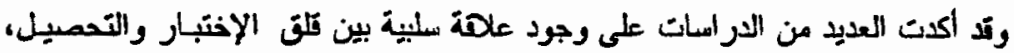

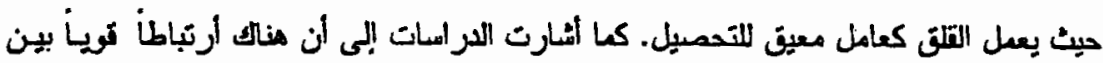

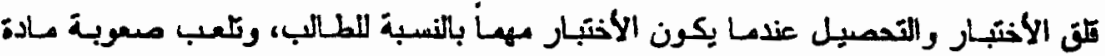

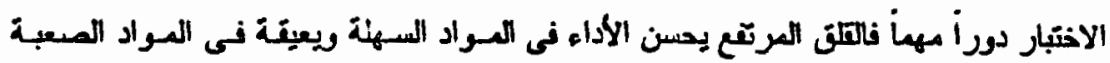

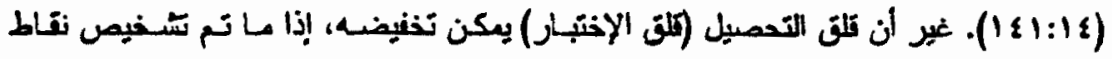
الضعف لدى العتعلم، وما يعانيه من معوبات، ووضع برنامج للعلاج، والتغلب عليها، والثمليل

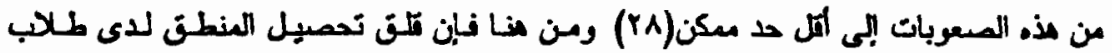

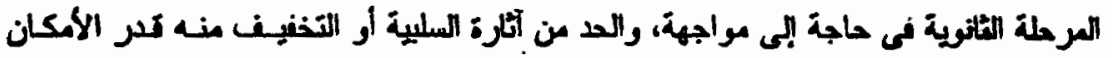
كسبيل لرفغ مستوى التمميل.

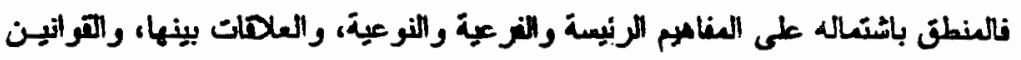

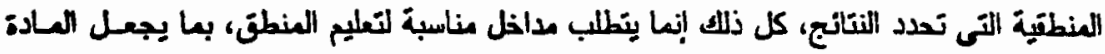

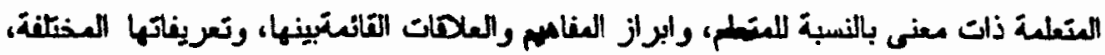

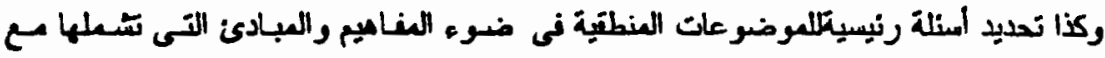

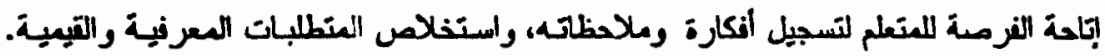

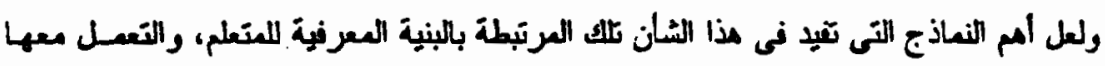

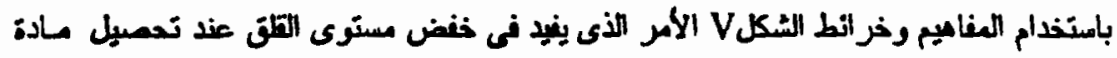
المنطق وبالتالى زيادة مسترى التعميل لاى الطلاب.

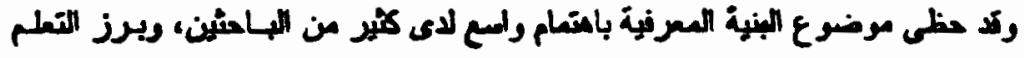

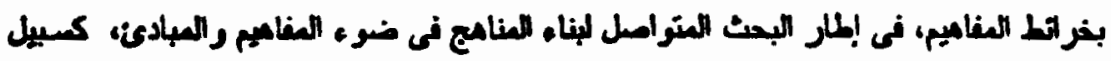




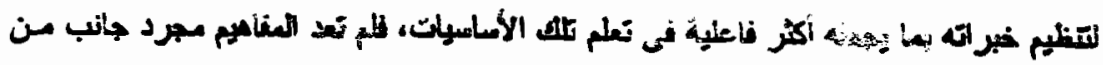

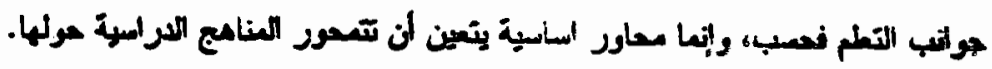

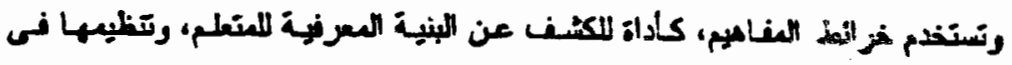

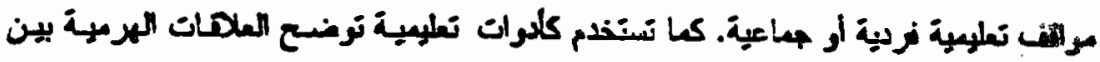

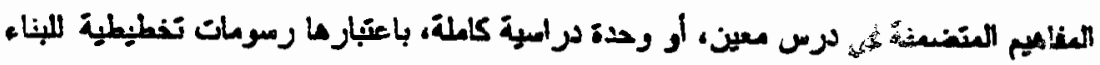

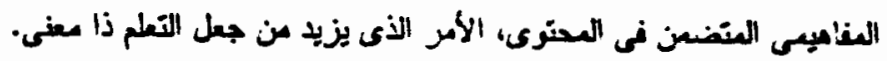

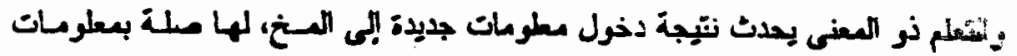

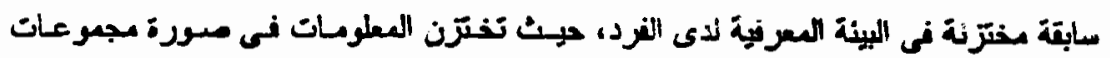

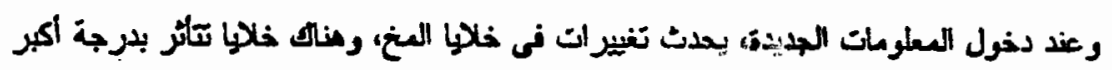

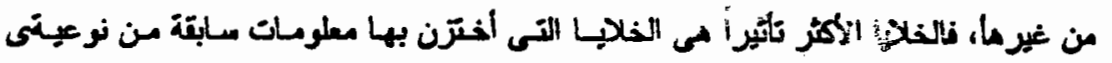

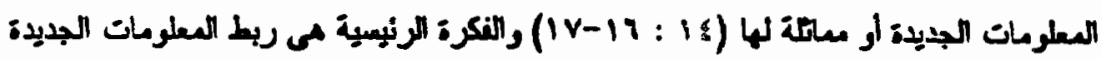

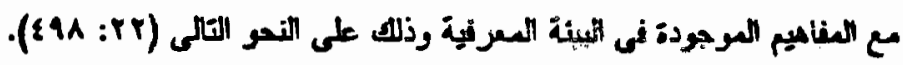

\title{
Subsumption
}

\begin{tabular}{|c|c|c|}
\hline $\boldsymbol{A}$ & $+a$ & $=A$ \\
\hline Existing concepts in & New Relavant & Moded Concept In \\
\hline Congnetive Structure & Information to be & Congnetive structure \\
\hline المفاعير الموجودة فى البينة & learned & مفامير معذة فى البينة العسرنية \\
\hline المعرنية & العلومات الوبديدا للى يتم تعلهها & . \\
\hline
\end{tabular}

شُكل (1) الفكرة الرئيسية للتطم ذى العنى

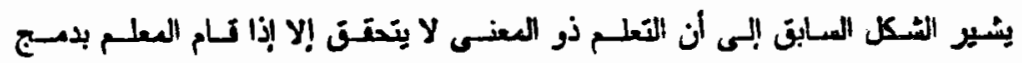

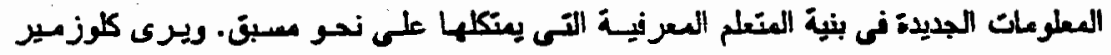

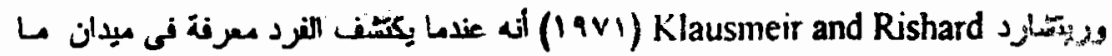

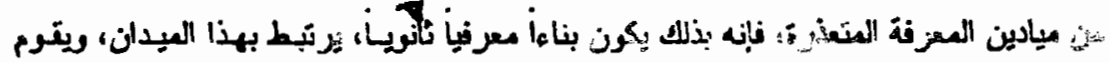

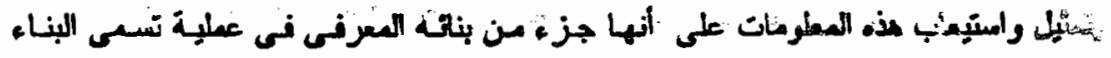

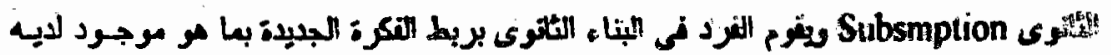




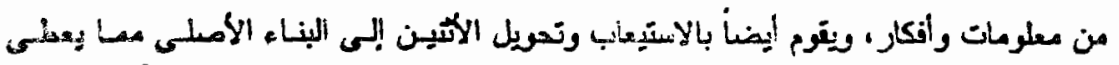

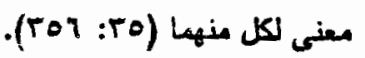

وتك تام نوفئل Novak وزملاوه فى جأمعة كررنل (19Y0) بتطوير نعرذج اللتعلم

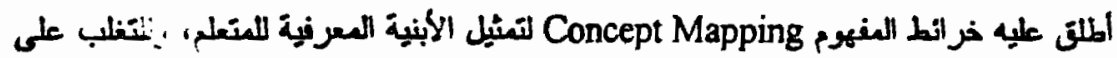

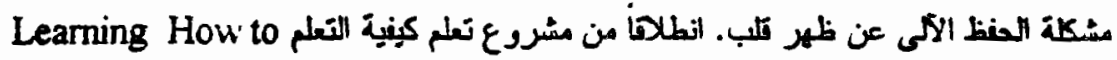

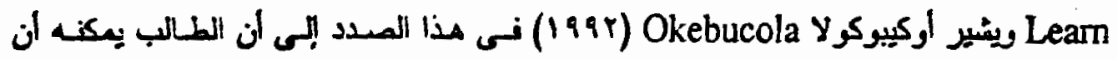

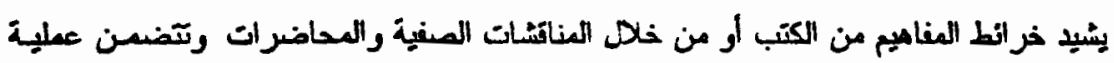

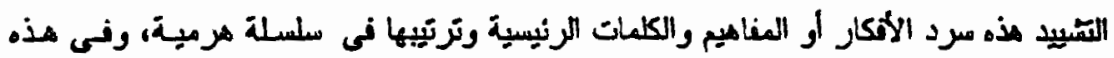

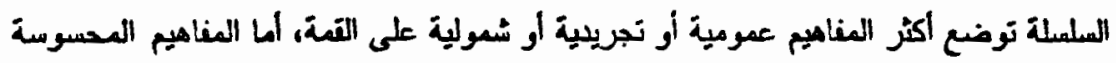

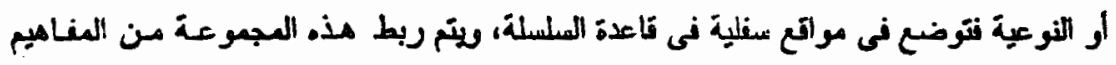

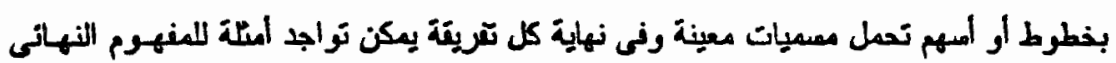

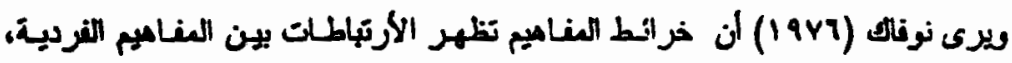

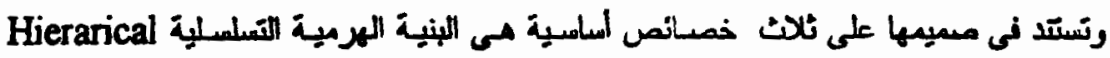

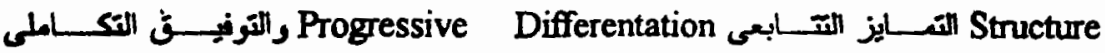
Integrative Reconcilliation

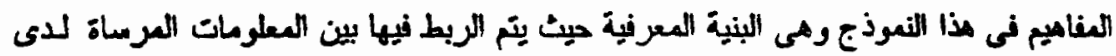

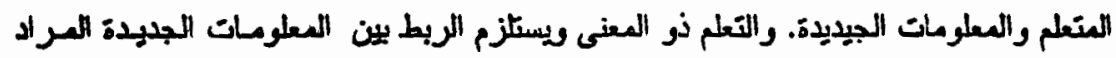

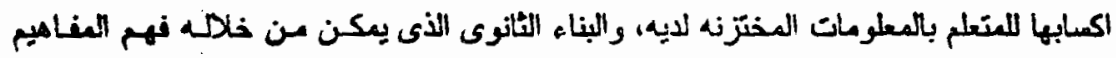

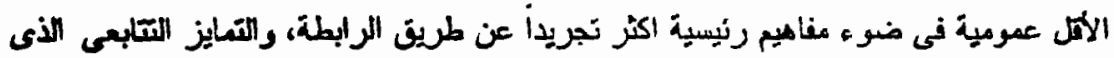

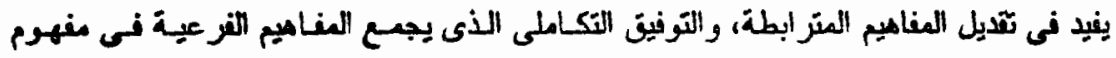

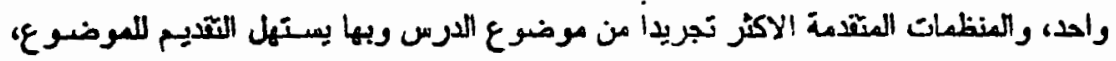

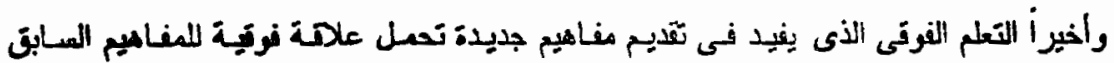

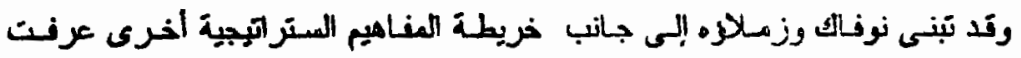

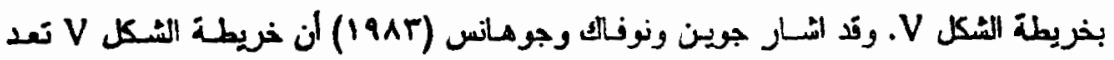
بعثابة اداة تعليمية توضح التفاعل القائم بيز البناء المفاهيمى، والبناء الاجراتس، لأى فر ع من 


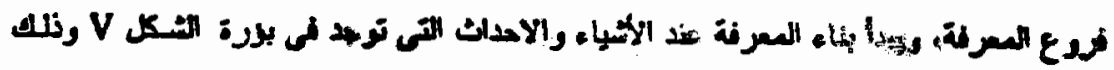

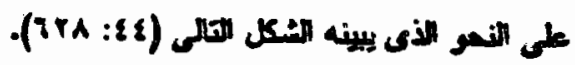

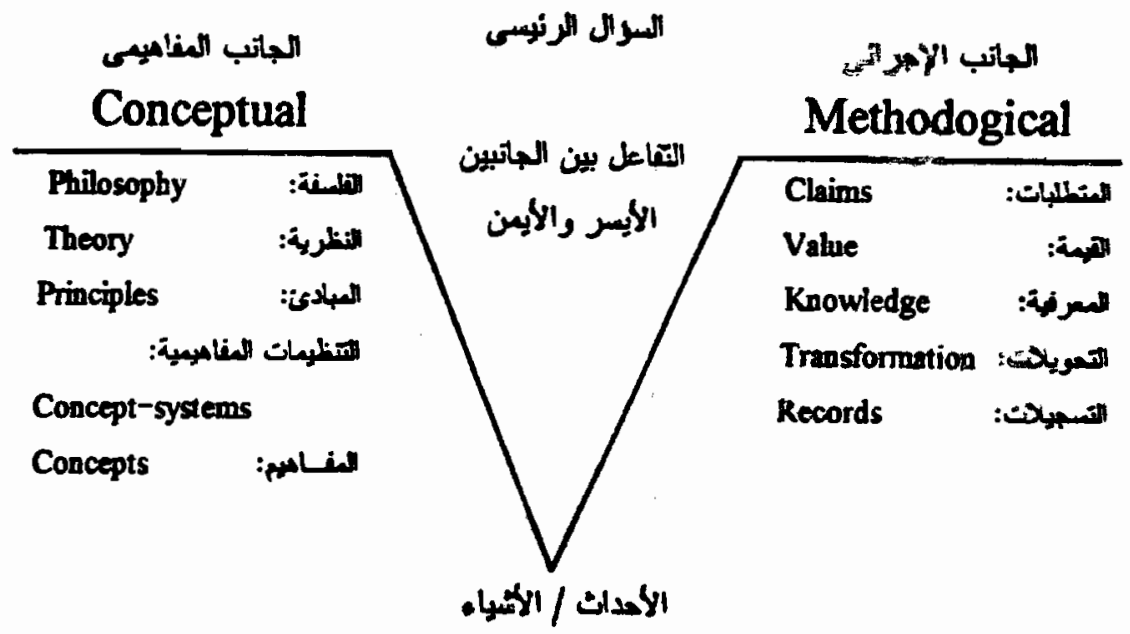

Event / Objects

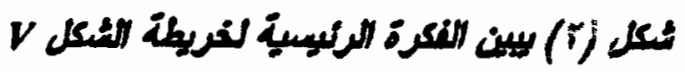

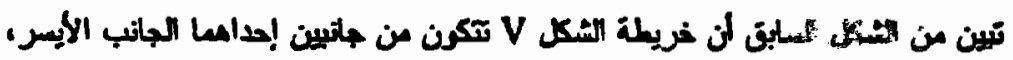

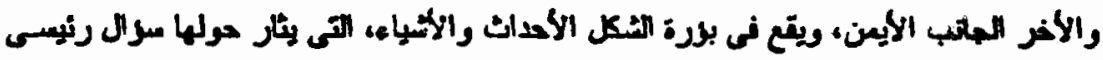

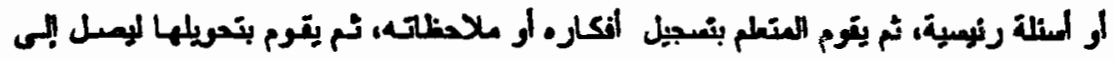

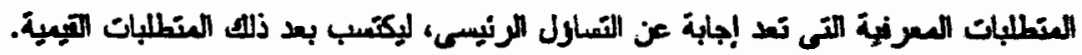

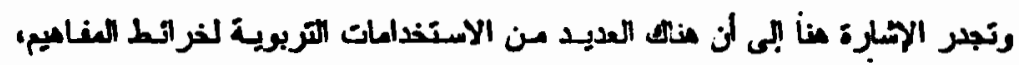

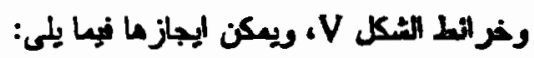

ا-نخطيط وتخظيم الهنهب:-

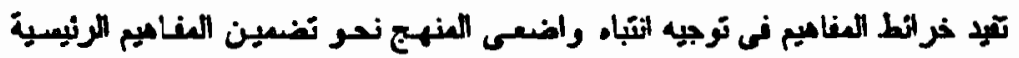

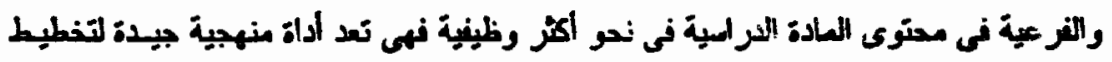

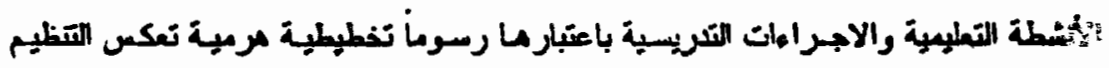

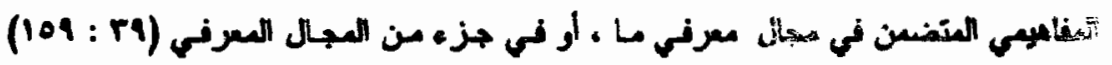

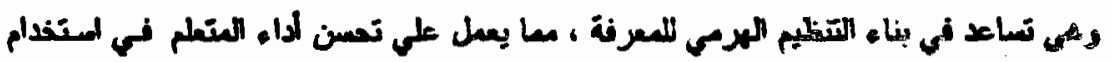




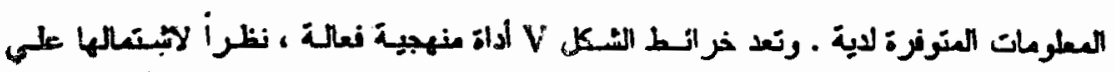

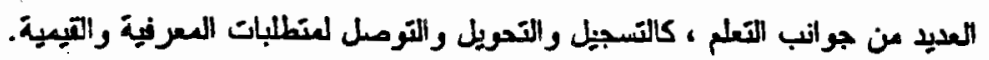

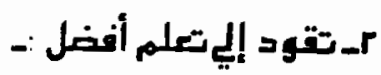

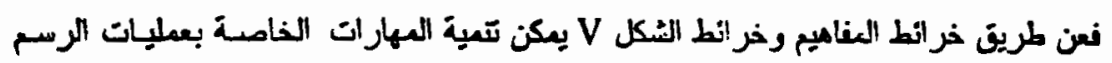

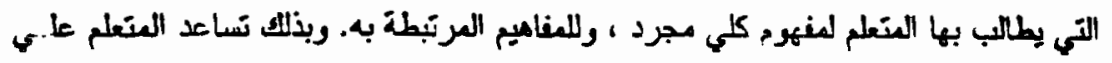

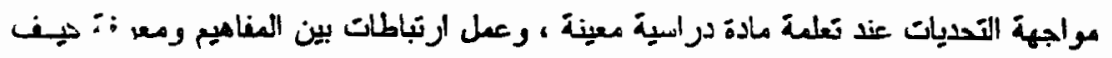

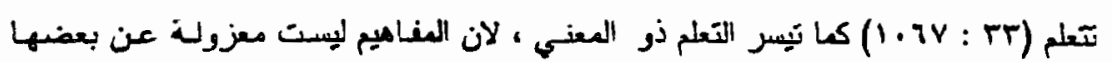

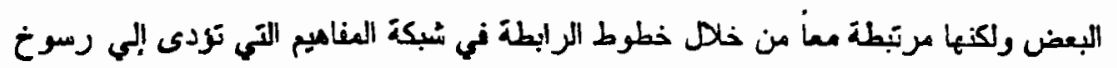

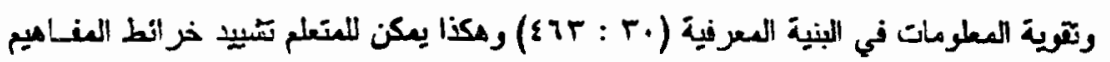

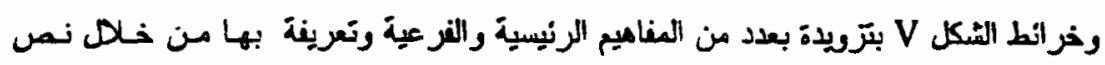

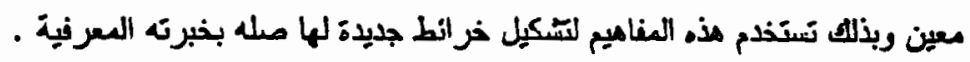

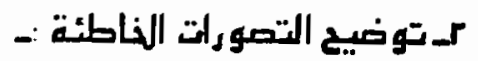

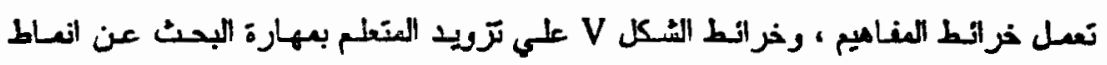

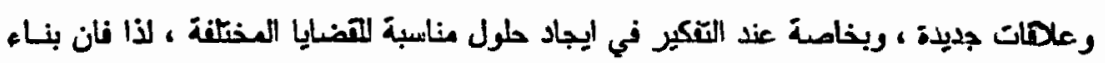

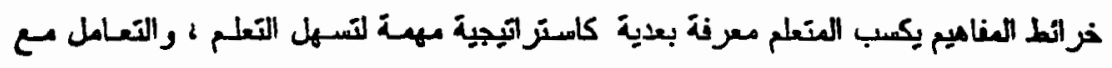

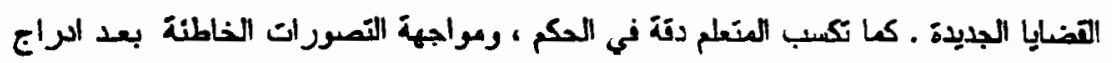

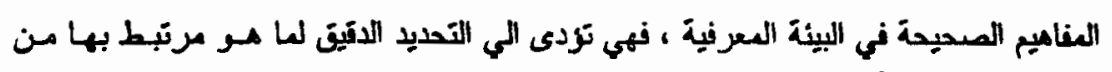

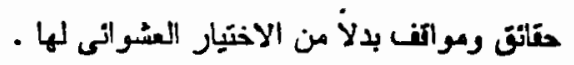

Eـ تشفيص وتتويم عملية التعلم -

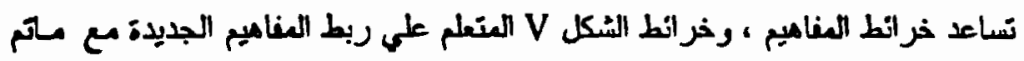

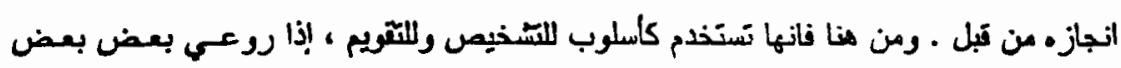

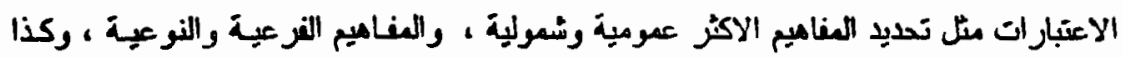

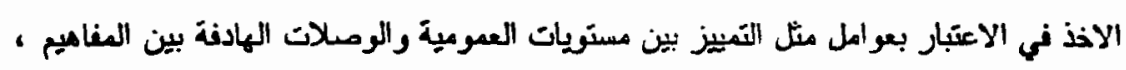

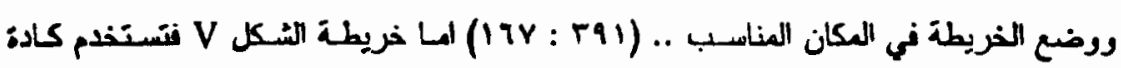

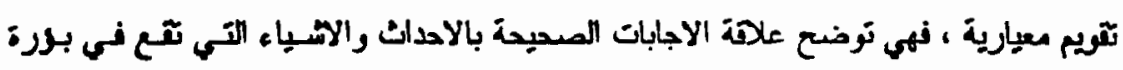

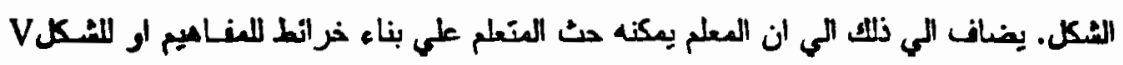
كسبيل للوصبول لي العبلومات والحقانق. 


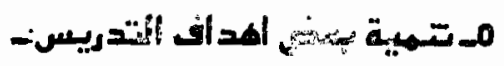

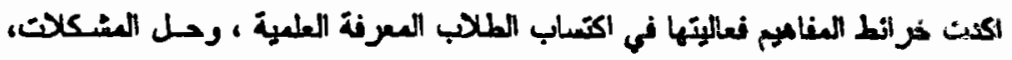

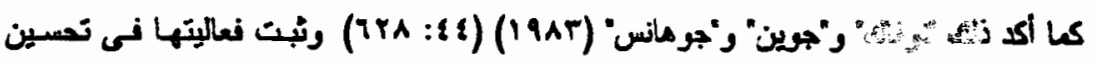

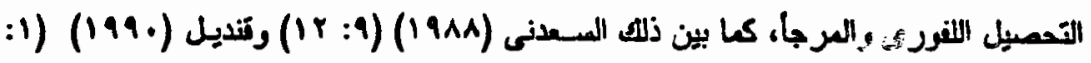

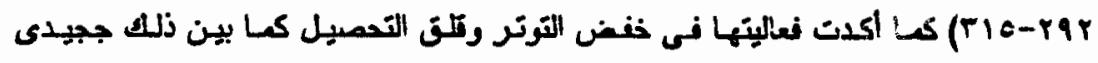

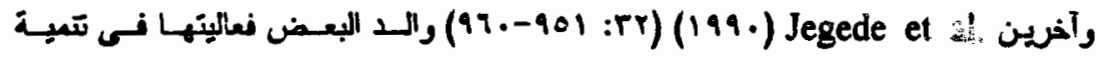

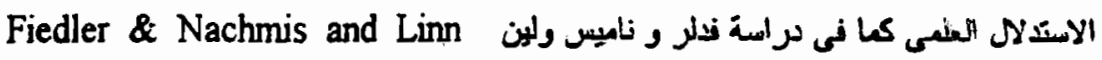
(191: IVr: : 19 (199.)

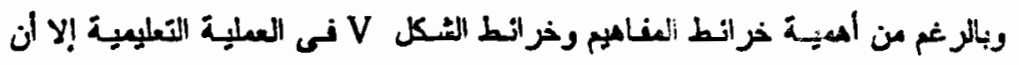

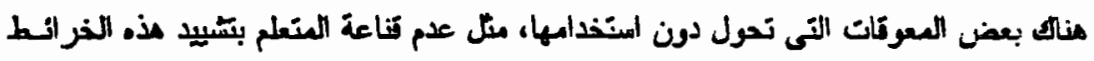

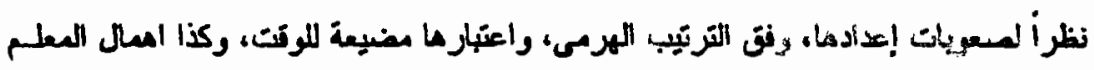

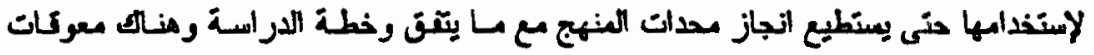

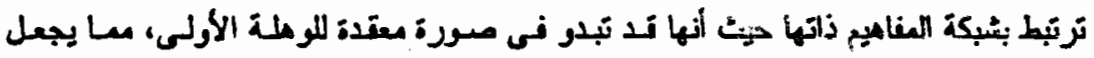

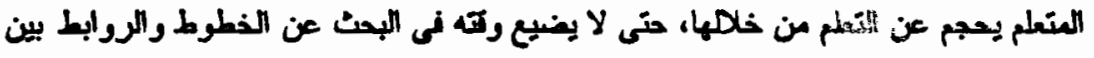

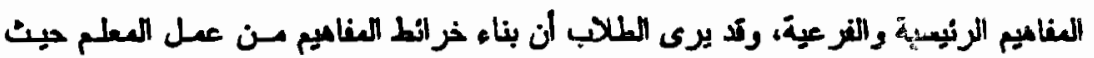

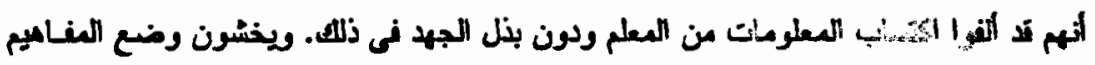

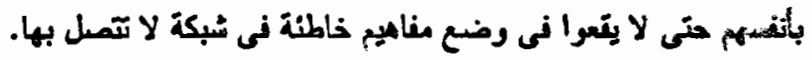

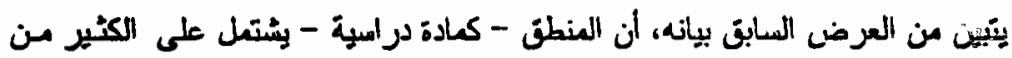

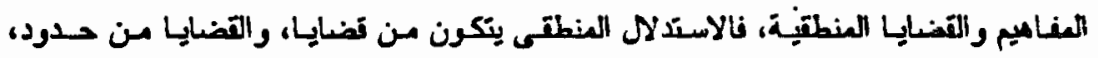
والحدرد فى حاجة إلى تحديد عن طرين التعريغات والنصنيفات والتمسيمات المختفة، لـذا نلين ععلية الزبطل يين التعريغات النظرية لمادة المنطت، رغم تثارت أفاظها وعبارنها يعل معربة بالفة لدى المنعلم ويكاد يصل حد المسوبة إلى كر المبية المتعلم للمادة والخرف من إختباراتها، سا يسبب لديه متفأ نحو تحصبلها فيطا يعرف بكلز تحميل مادة السنطن.

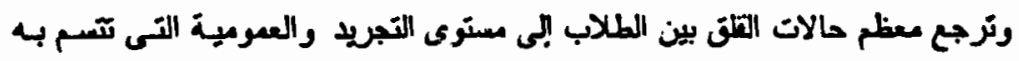

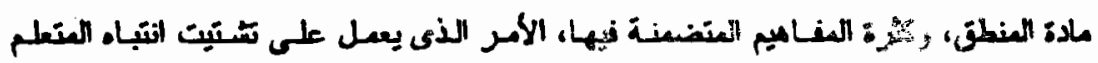

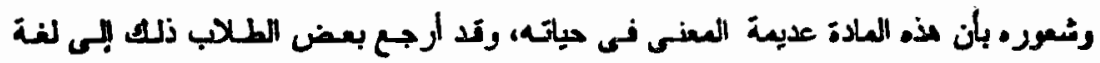




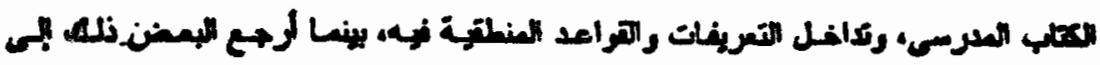

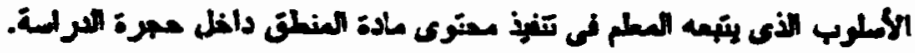

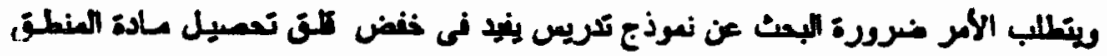

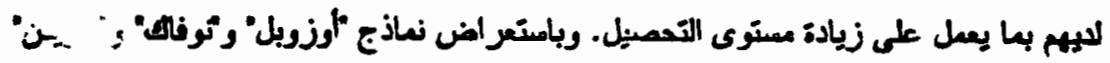

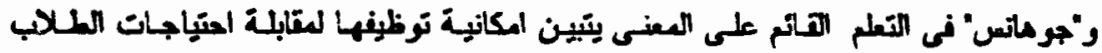

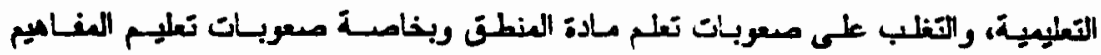

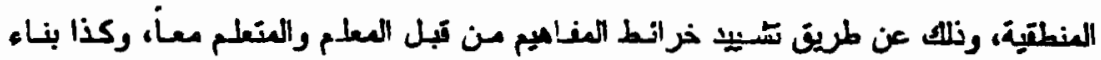

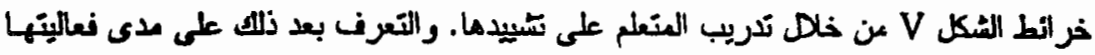

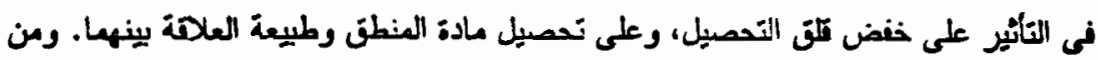
هنا تحدنت مشكلة البحث:-

\section{مشكالة البحث:.}

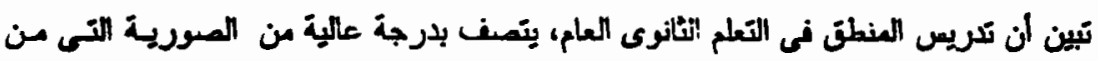

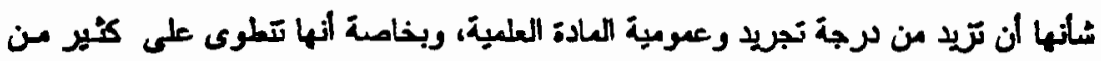

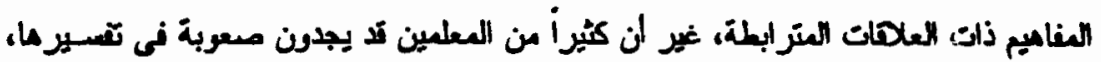

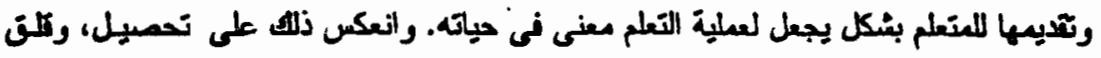

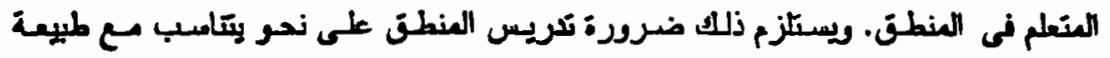

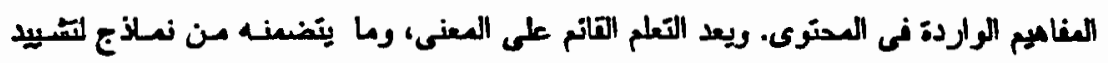

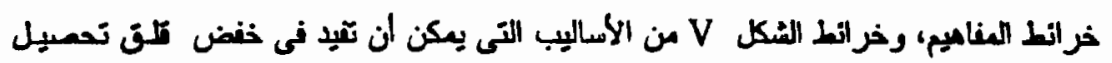

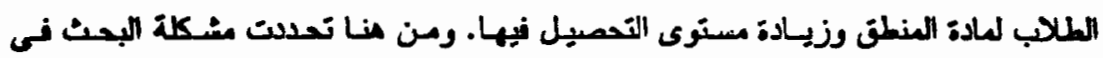

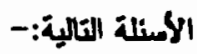

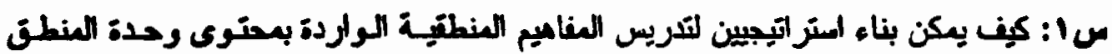

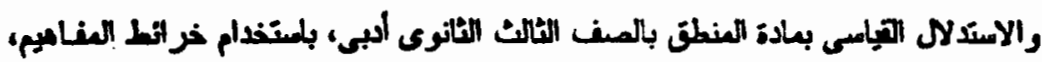

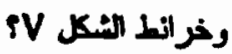

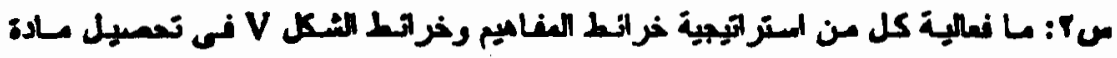
"المنطون

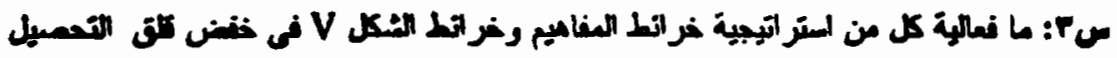




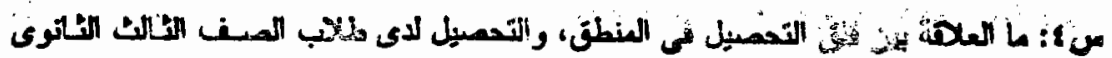

أدبر

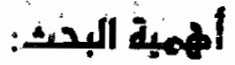

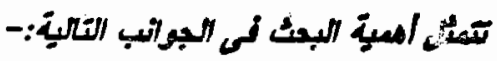

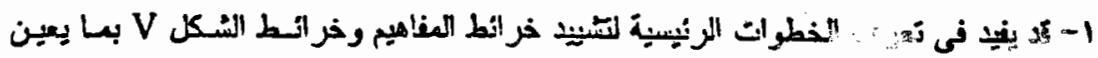

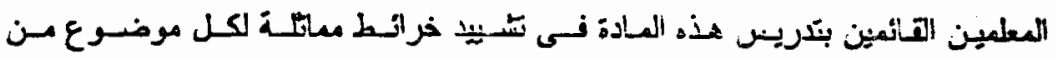

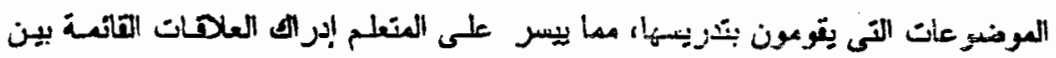

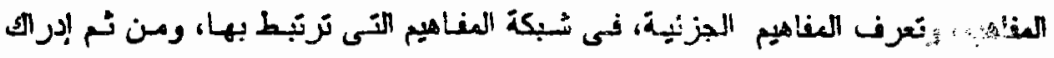

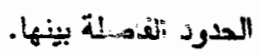

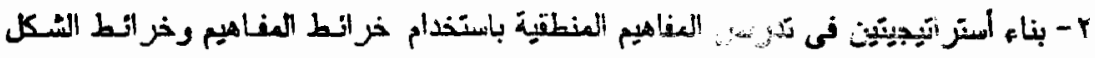

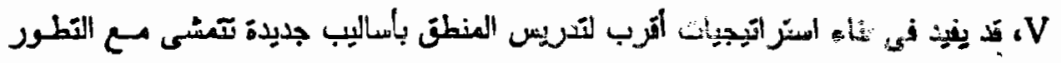

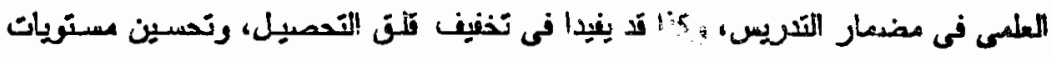

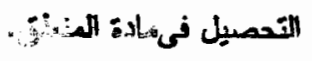

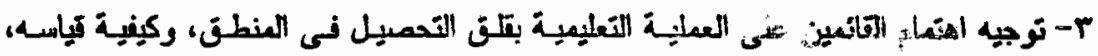

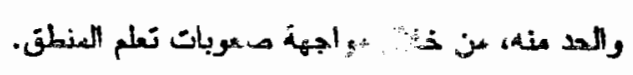

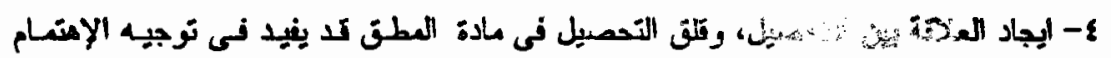

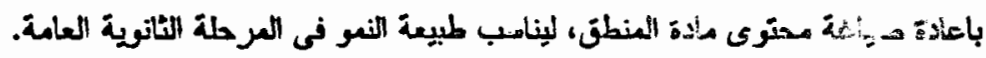

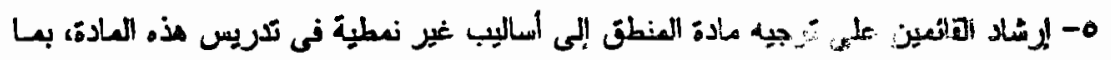

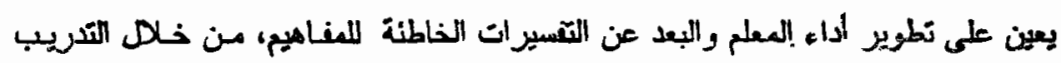
العسنعر على يناء الخر ائط الفناهيبنة.

\section{حمود البحث:

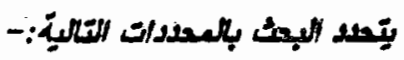

1- الاهصار على عينة من طلاب الصف الثالث الثانوى الببى بعدينة المزازيق.

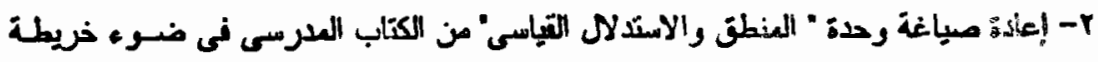

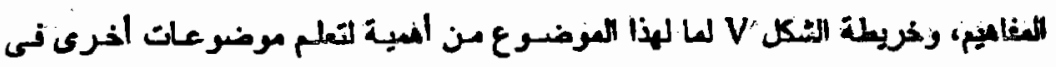

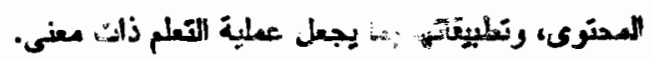

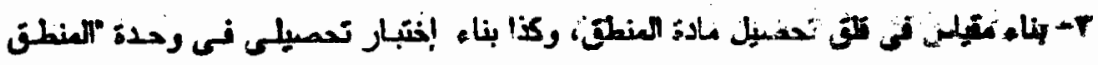

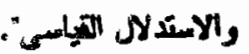




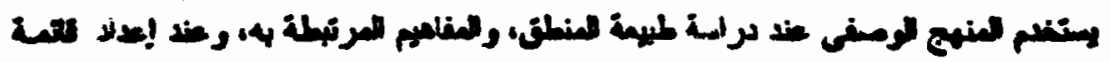

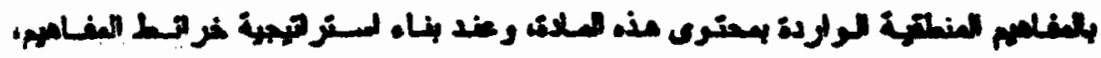

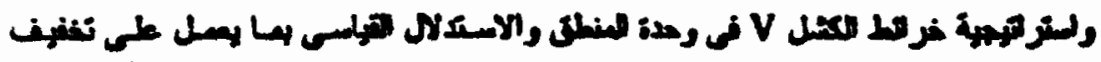

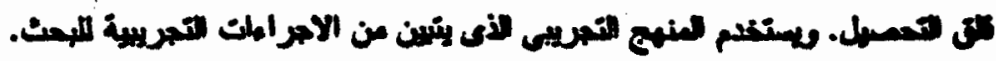

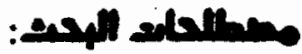

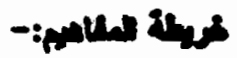

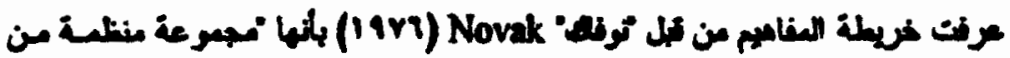

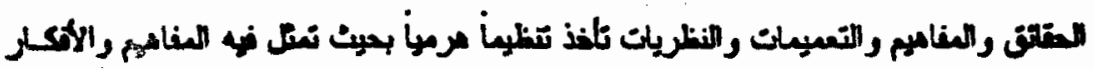

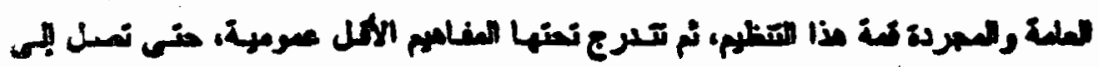

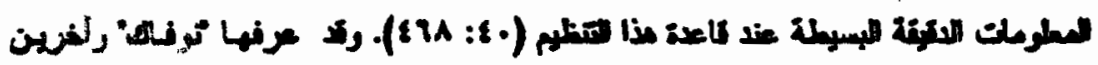

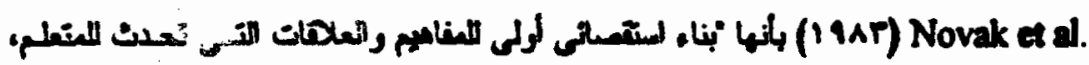

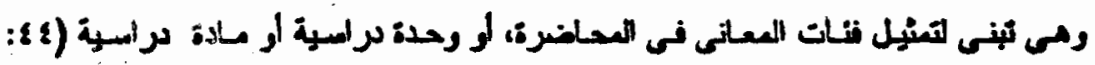

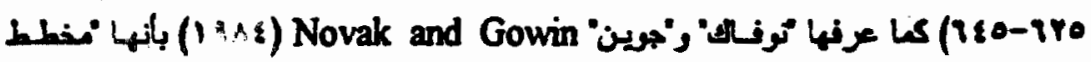

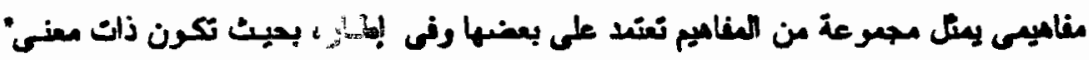

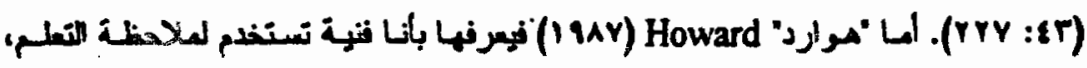

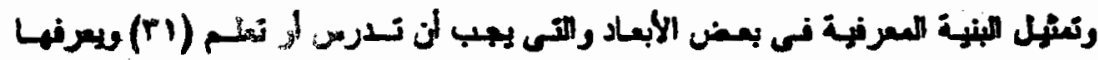

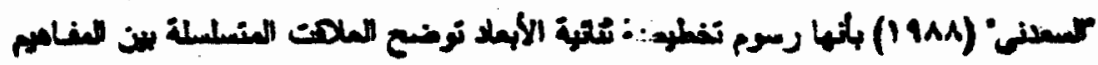

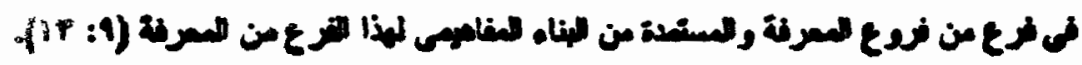

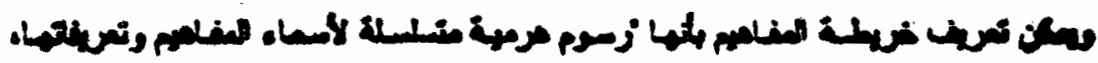

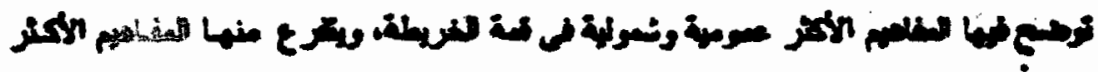

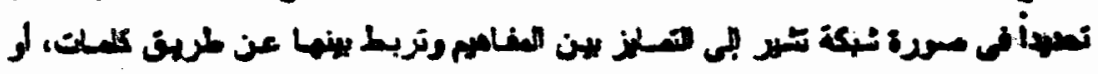

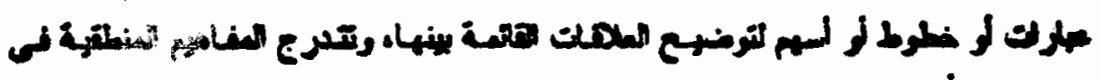

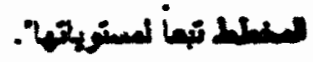

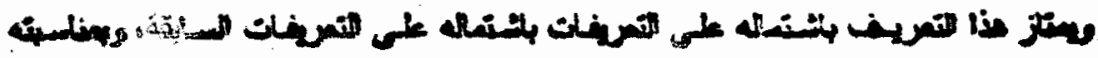

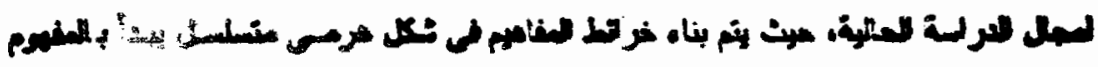




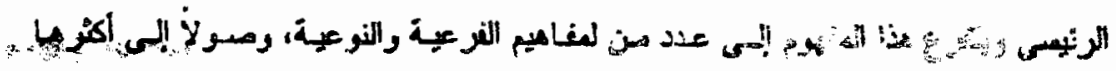

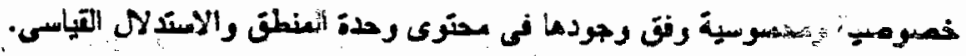

:

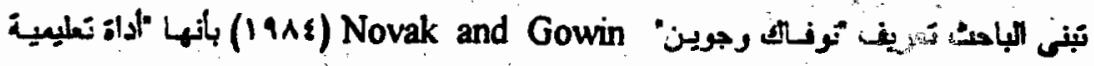

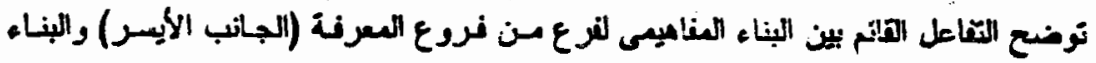

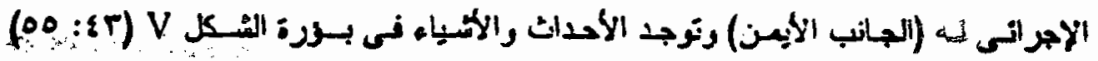

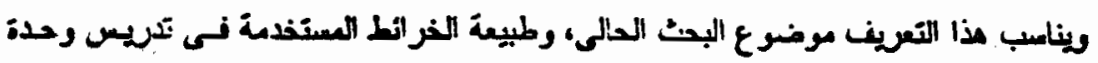

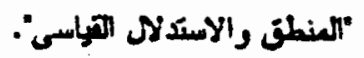

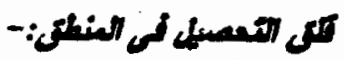

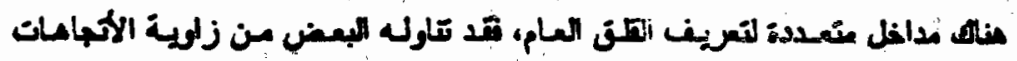

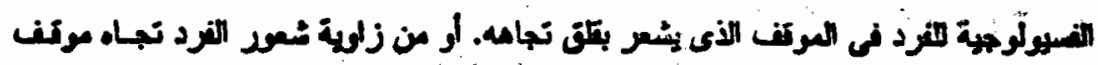

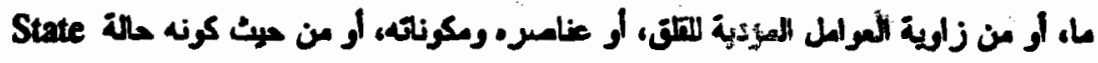

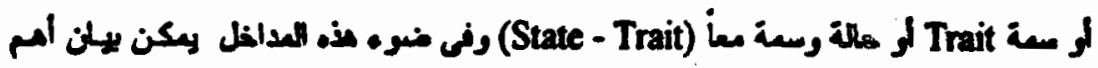
مذه التصنيفت.

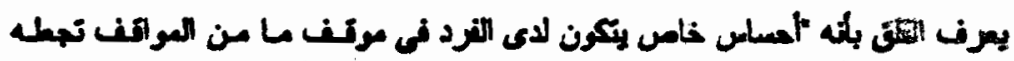

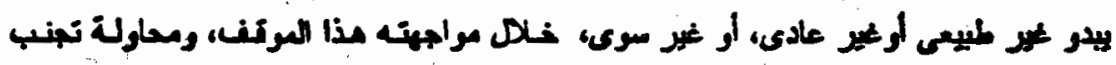

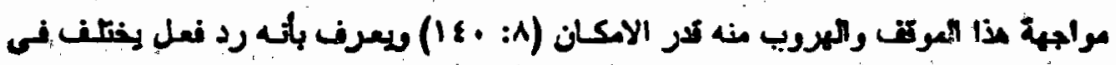

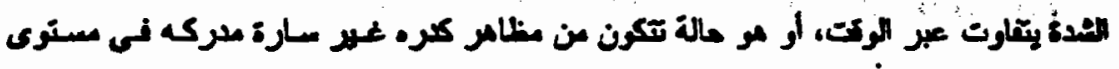

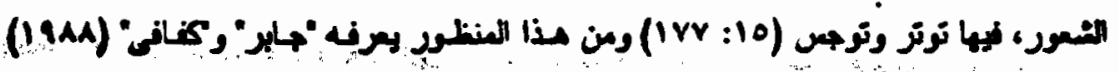

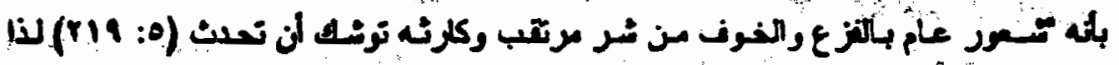

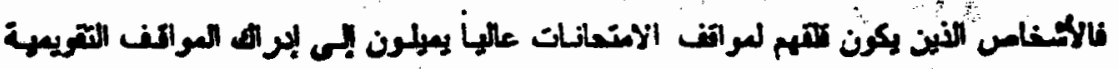

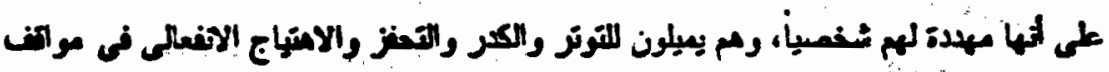

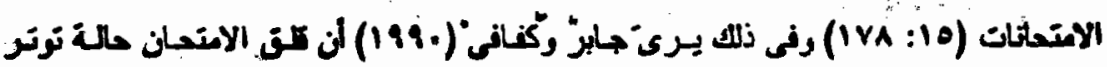

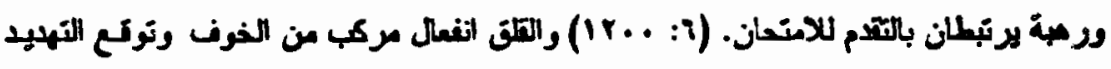

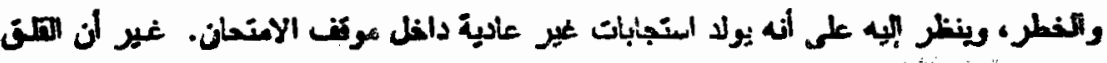

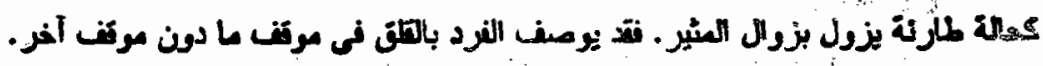




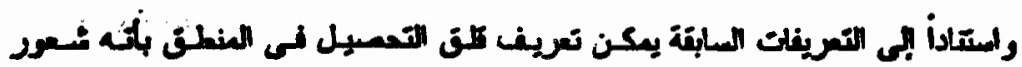

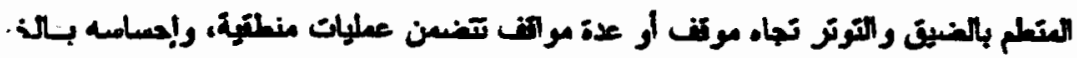

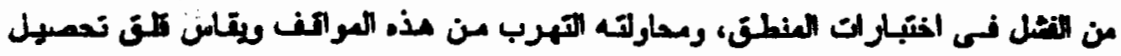

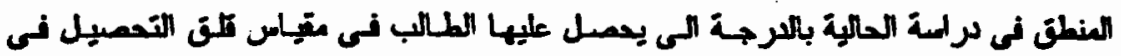
العنطق الأى اعده الباحث.

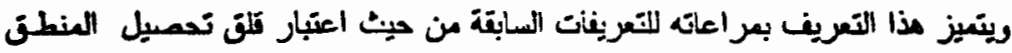

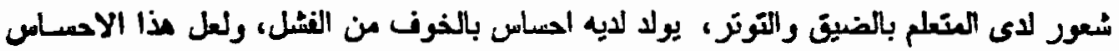

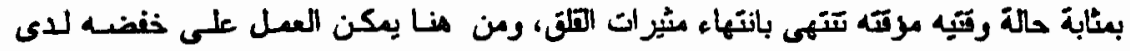

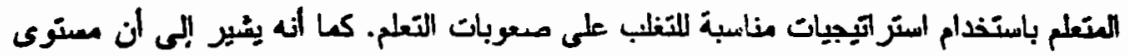
الهتى لاى العتعلم يتحدد بدرجتة فى مقياس بعد لهذا الغرض وبالتحديد فى مادة المنطن. الصراسات السابقة: تميزت الاراسات العابقة بالتعدد والتتوع فيما يتعلت باستخدام خر ائط الفاهيم وخرائط

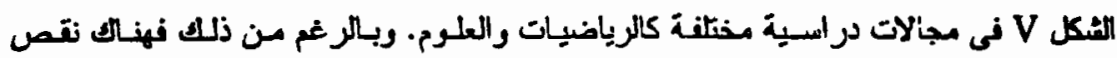

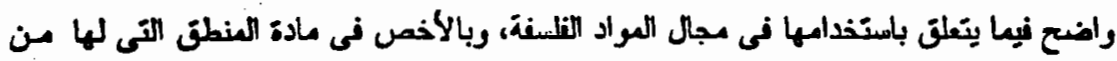

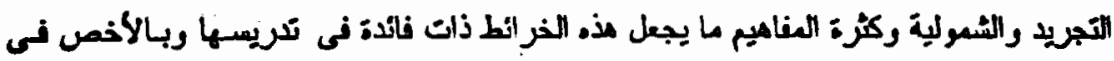

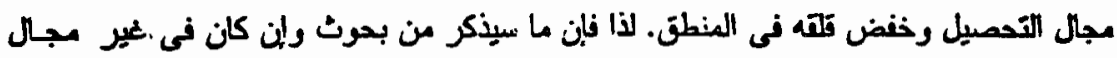

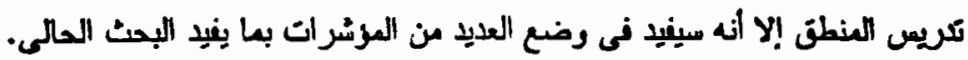

\section{أولا، دراسات اهتمعت باستخدام خرائط المغاهير وخرائط الشكل}

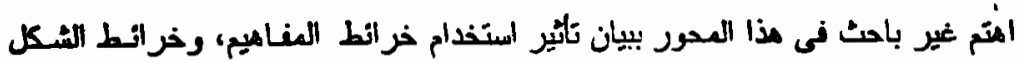

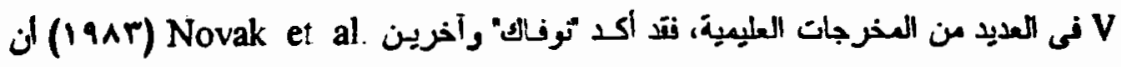

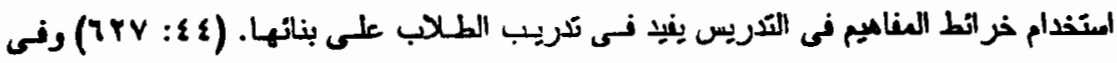

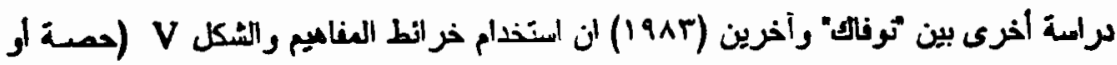

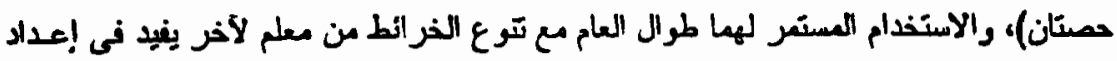

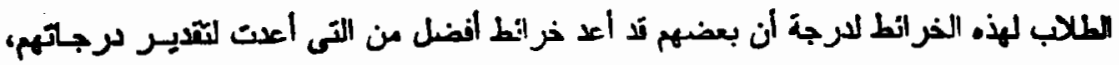

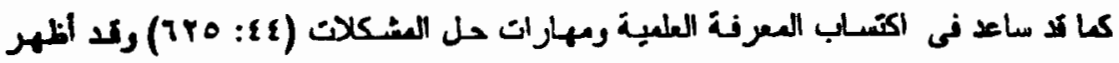

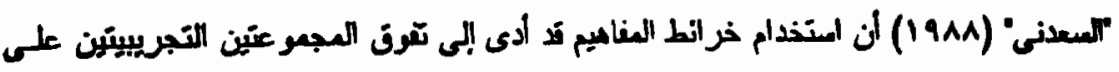

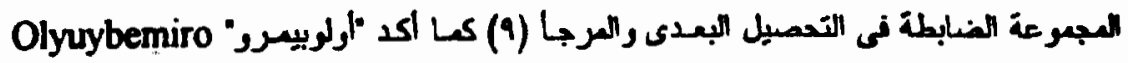

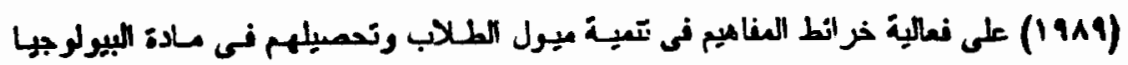




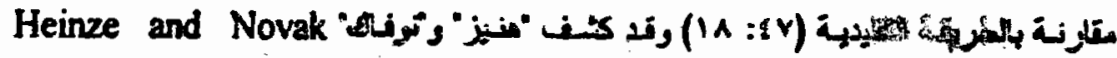

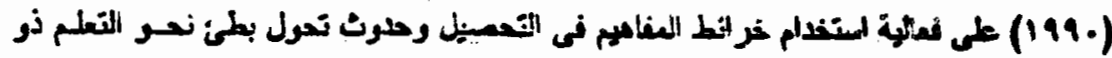

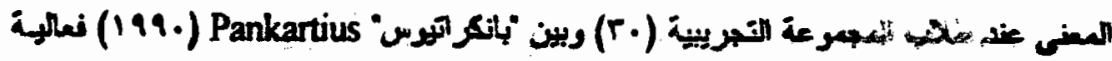

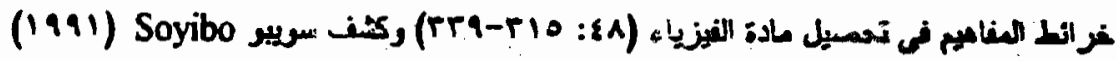

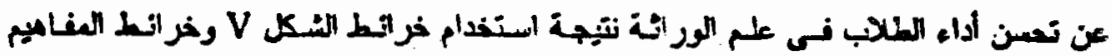

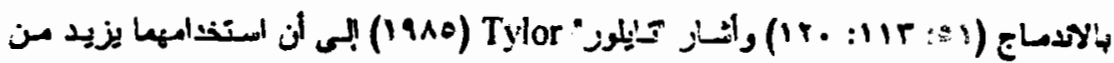

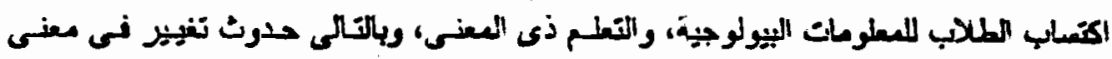

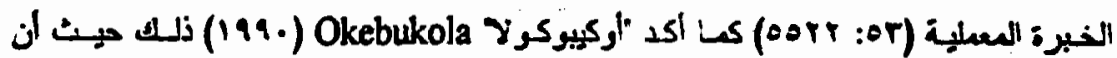

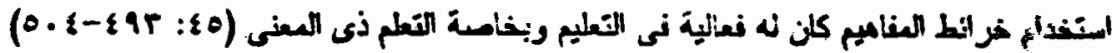

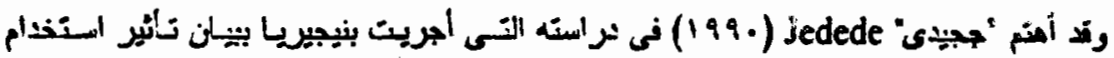

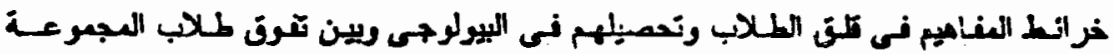

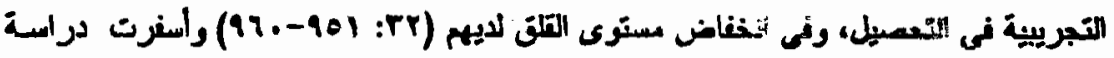
"اوكييركول لkebukola

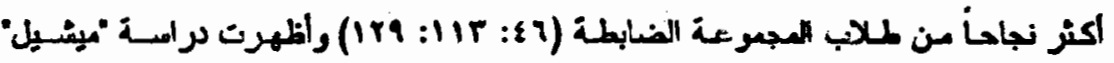

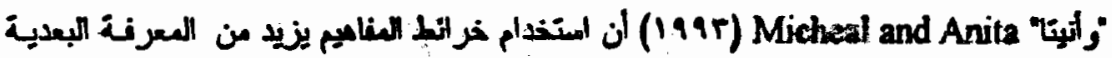

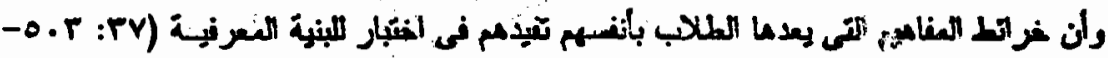
(ors

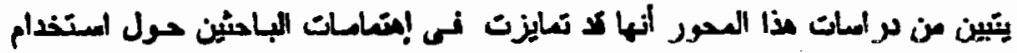

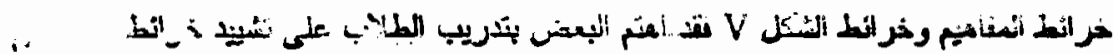

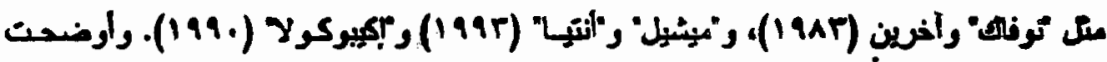

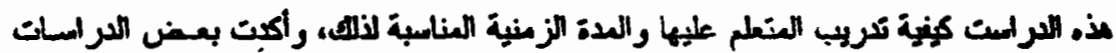

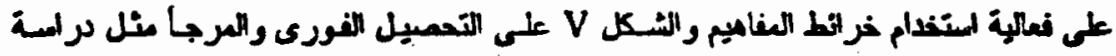

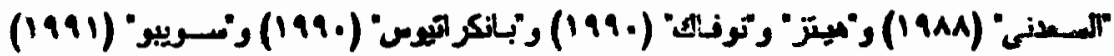

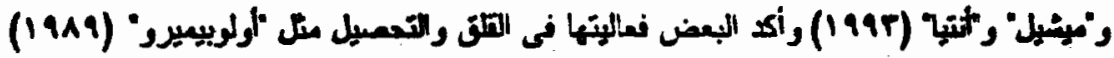

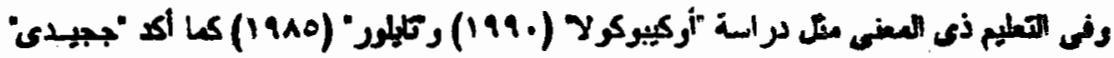

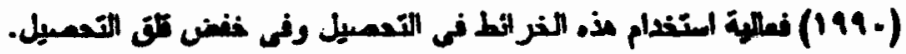

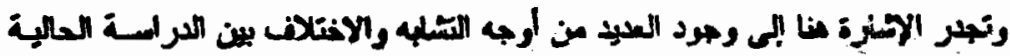

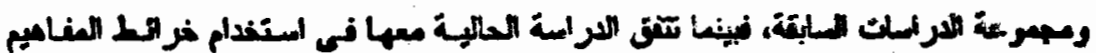




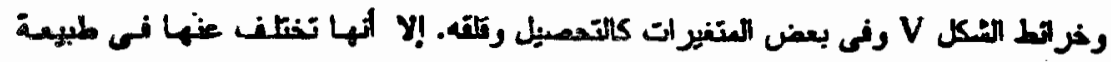

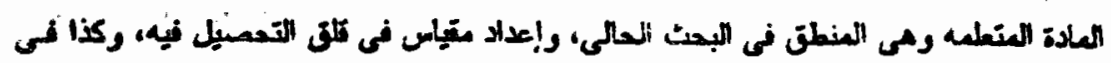

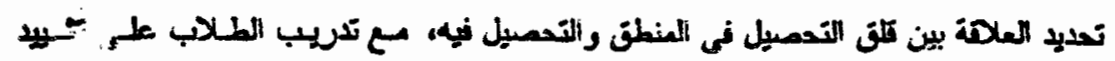

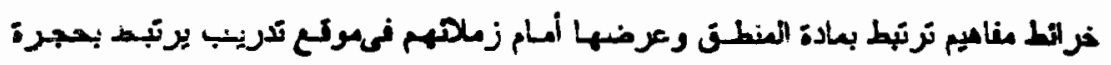
الدراسة فى إبلار التعليه الجعى المنبع فى مدارسنا.

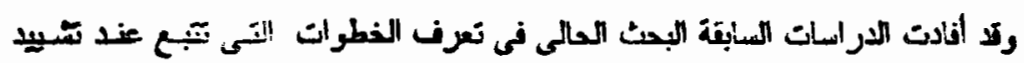

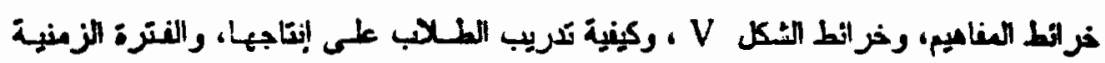

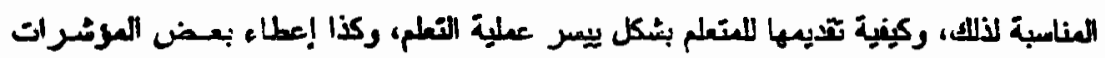

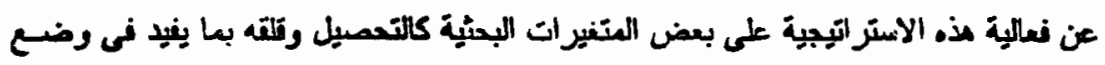
نروض البحث.

\section{ثانيا: دراسات اهتمت بهنفر قلق التهصيل في المواد الدراسعية}

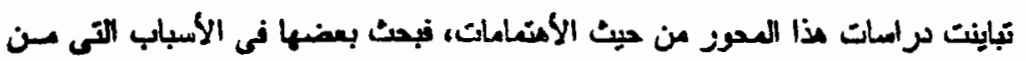

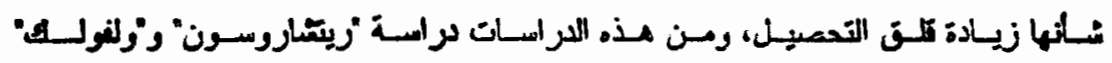
(YA) (19Ar) Frye (YAA-rVI:0.) (19A.) Richardson Iwoolfolk

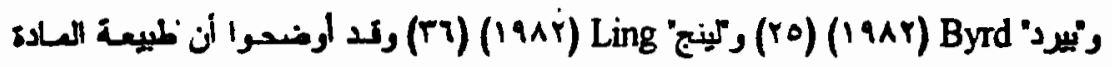

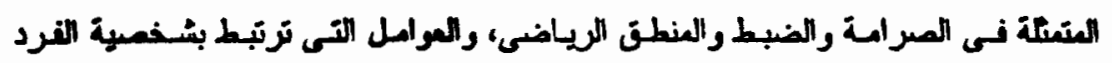

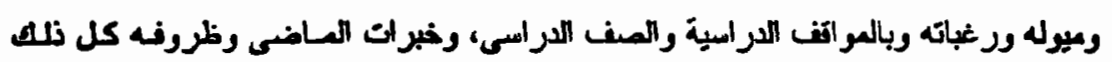

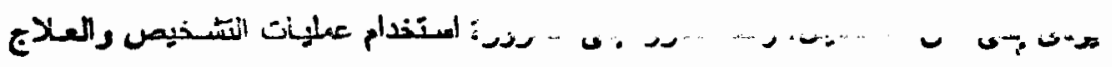

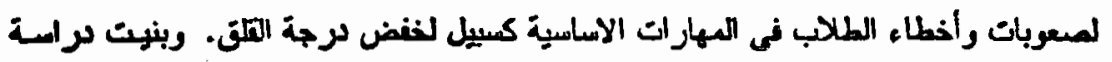

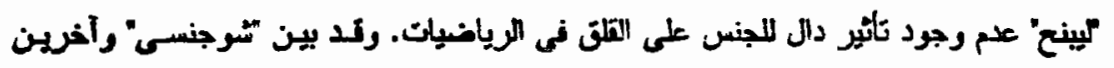
الماه Shaughnessy

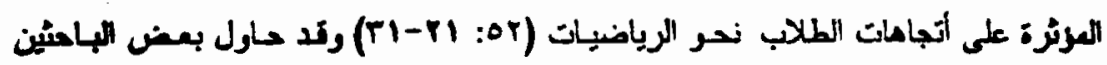

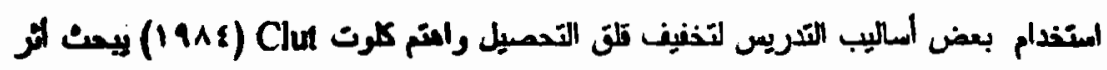

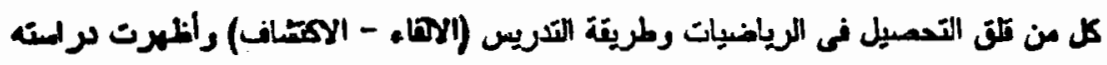

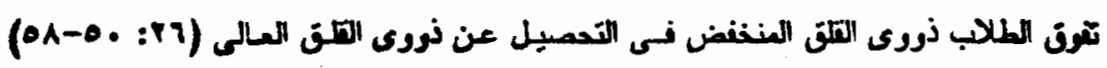

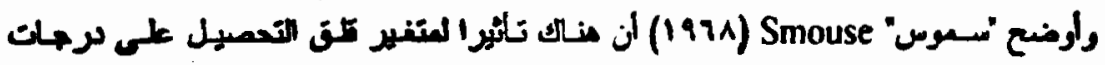

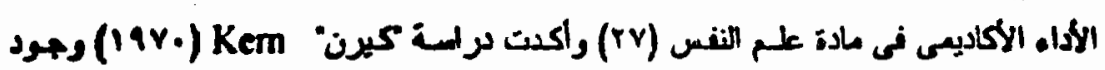




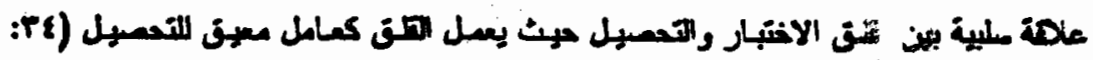

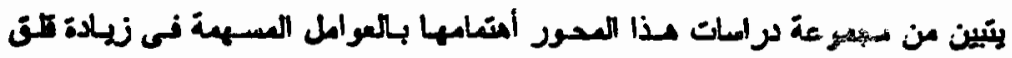

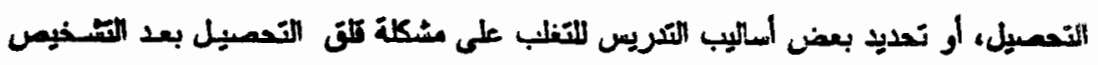

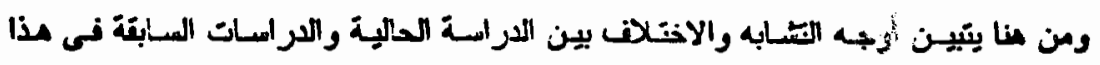

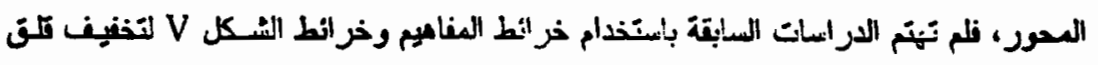

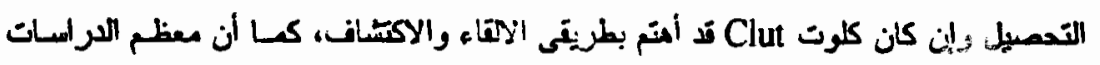

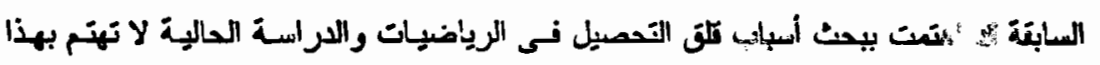

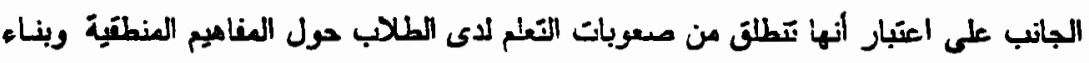

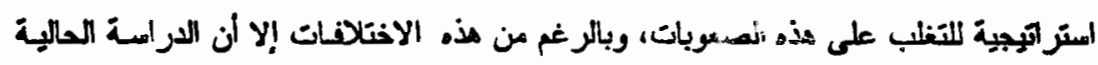

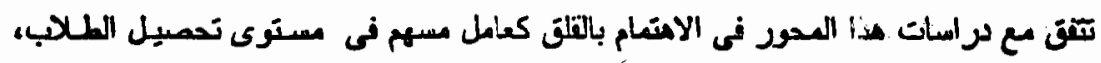

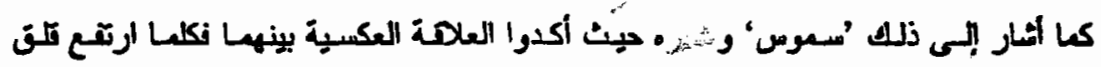

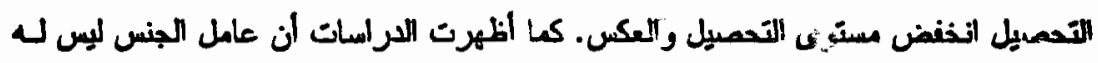

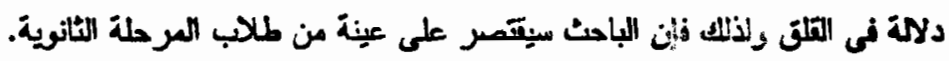

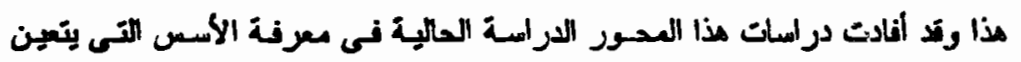

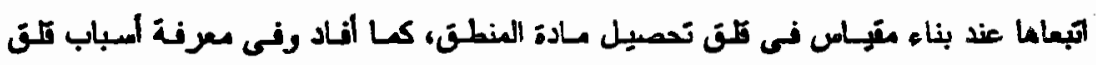

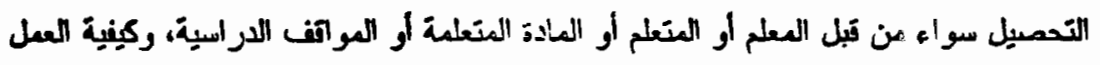

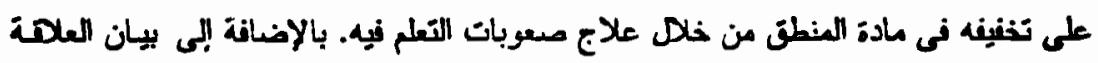

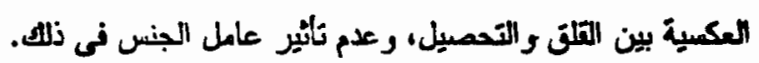

نهروض اليحث:تعضف العراسنة العالية إلى التعتق من صعة الفروض التالية:-

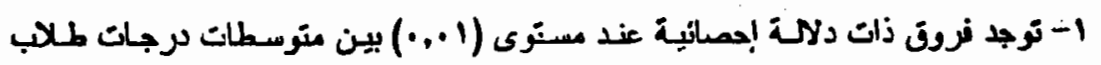

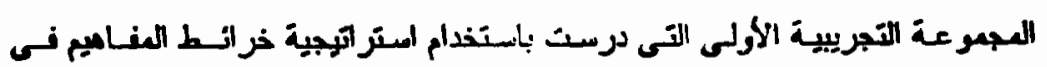

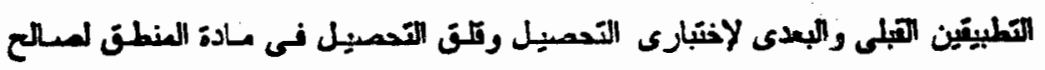
التطبيز البعدى. 


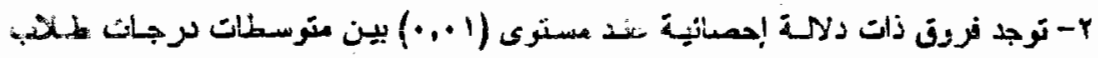

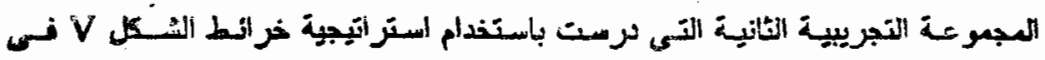

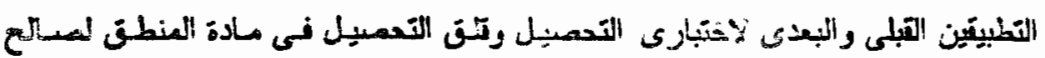
التطبين أبعدى.

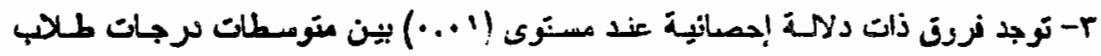

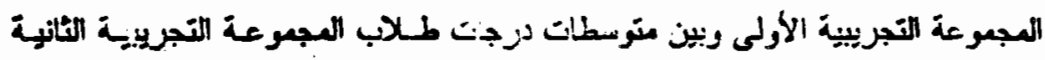

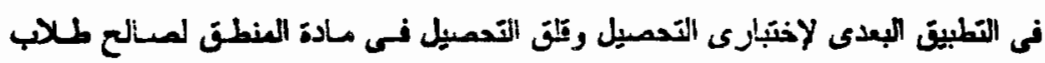

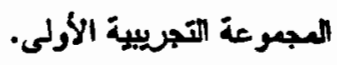

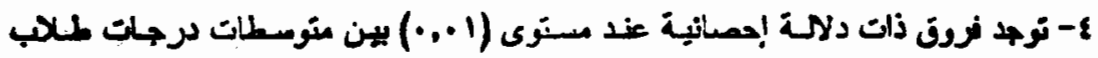

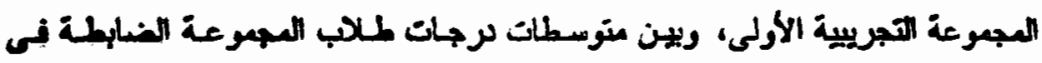

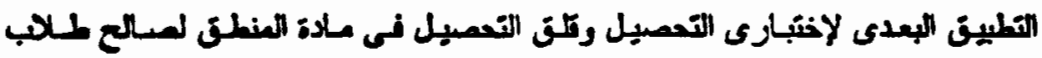

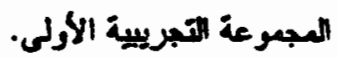

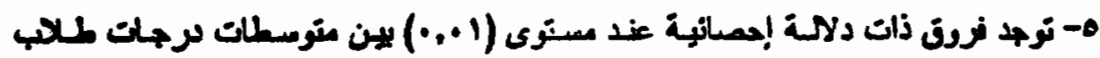

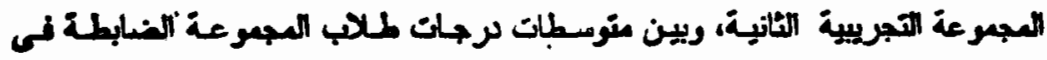

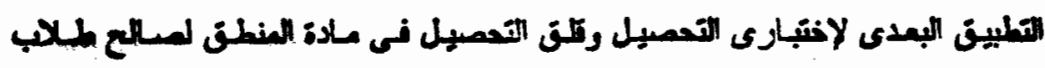
العجعوعة التجريبية الثانية.

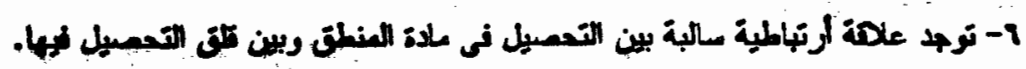

$$
\begin{aligned}
& \text { إبراهات الدراسة:- }
\end{aligned}
$$

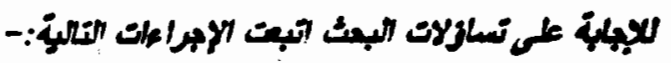

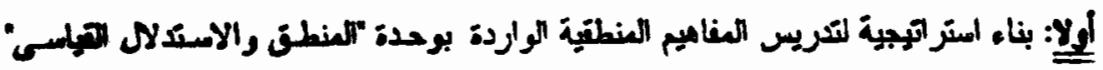

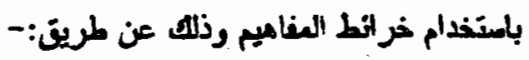

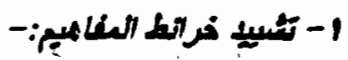
سعيت خرائط العامير وفق الذطوات التزلية:- 


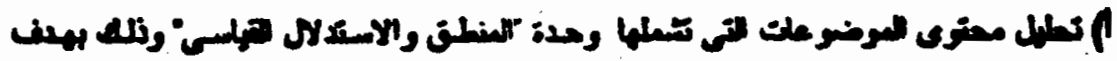

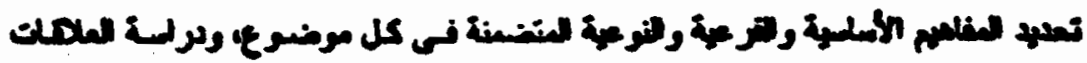

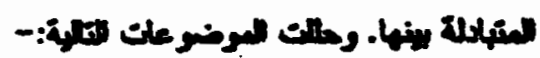

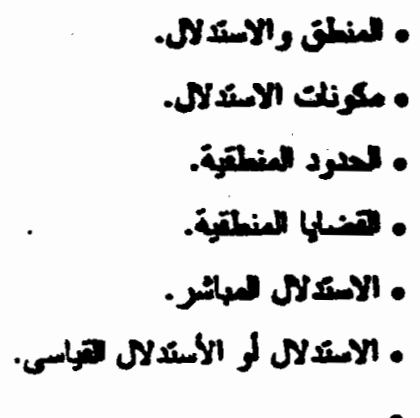

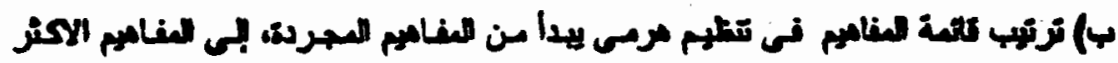

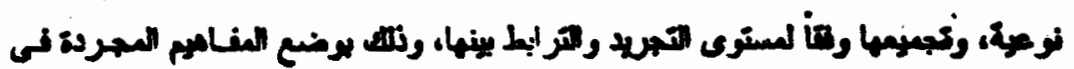

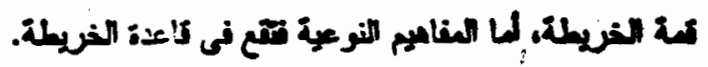

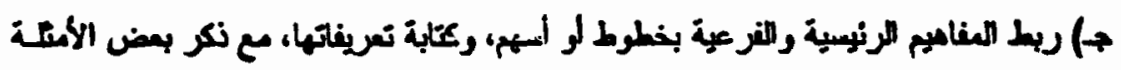

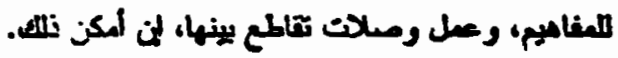

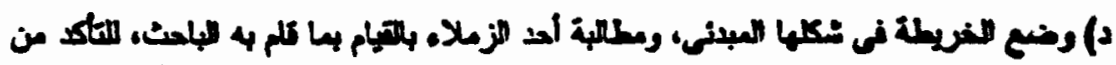

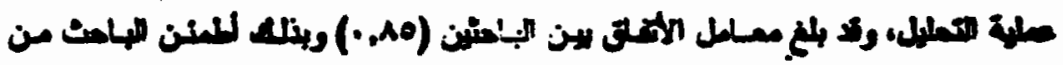

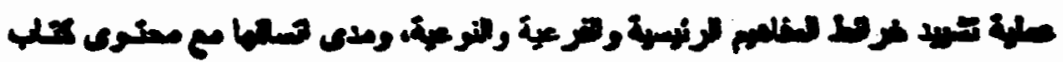

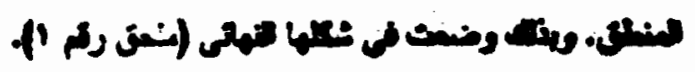

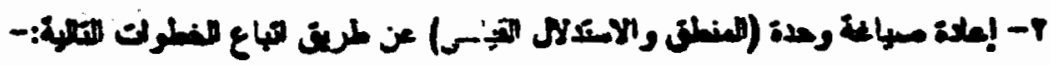

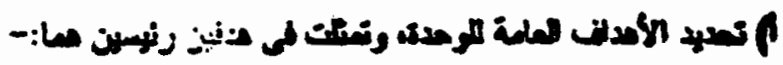

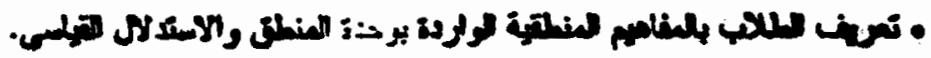

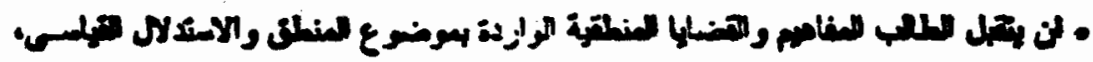

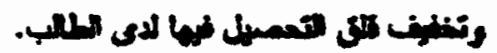

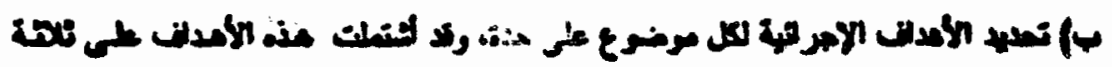

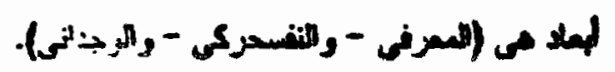




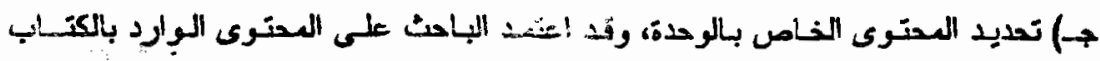
العدرسى لمادة العنطق.

د) استخدام خرائط الفاهيم فى تدريس العفاهيم المنطتية، وذلك عن طرين:-

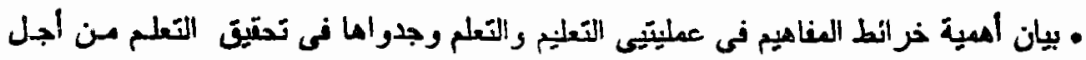

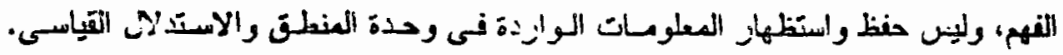

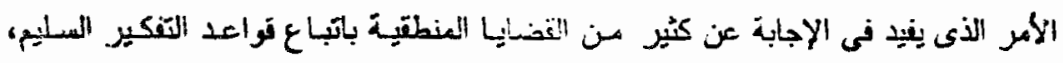

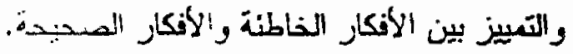

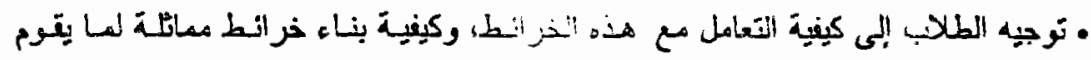

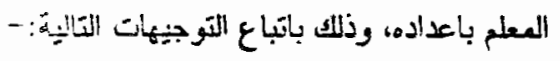

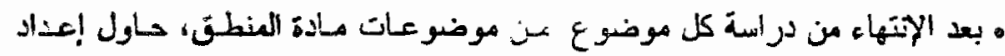

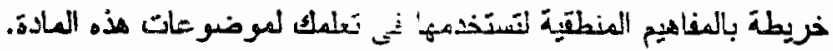

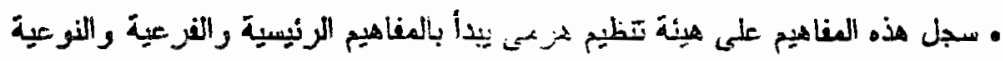

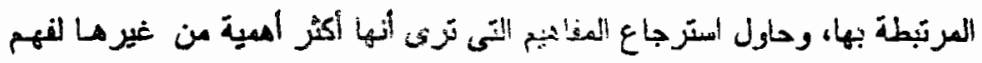

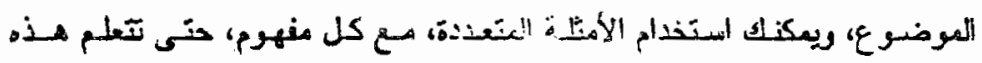

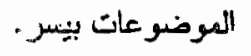

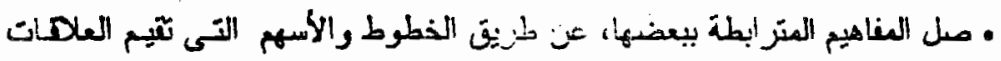

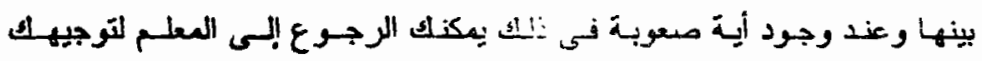

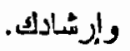

• يطلب من كل متعلم عرض الخريطة التى توصل اليها المام زملاهه مع مناقتشته فيها، وبيلان

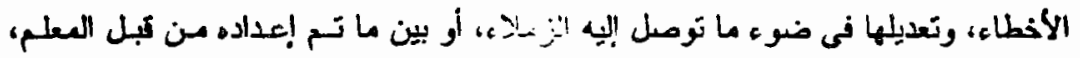

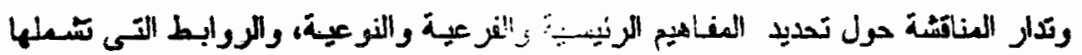
والأمثة التى نعبر عنها.

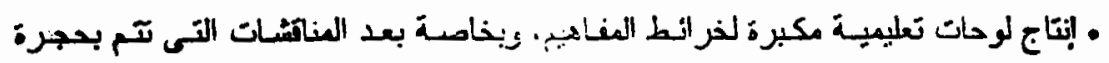

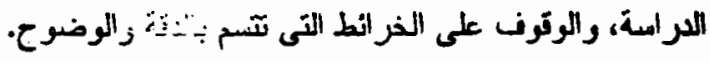
r- القتميم الفهاتى لكل مرس على حدة، وللوديذ ككل بعد ذلك.

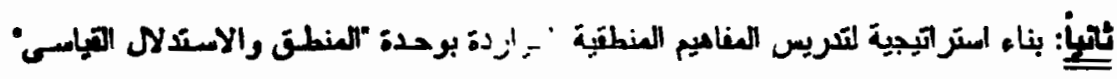

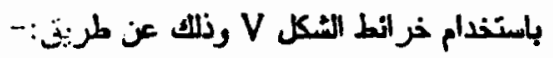




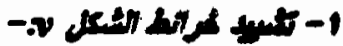

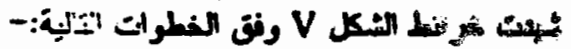

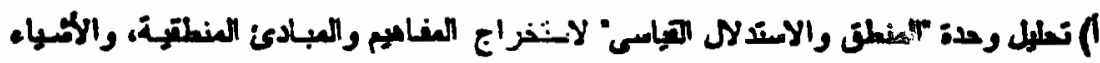

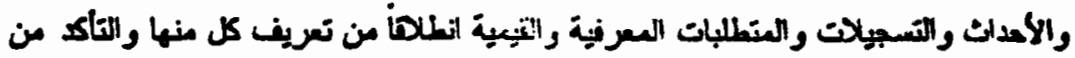

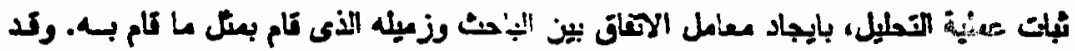

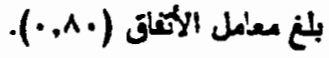

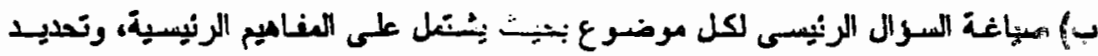
العوضوعات العنبّنَّة من التسارل الرئيسى.

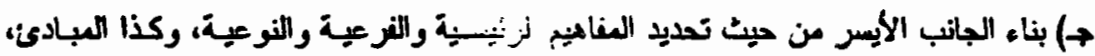

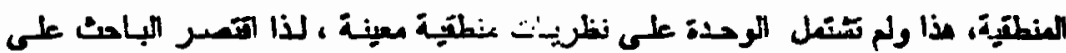

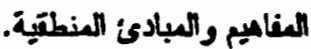

د) بناء الجاتب الأيدن · من حيث تعديد التسجيلات التى تئلبها الاجابة عن التساول الرتيسى،

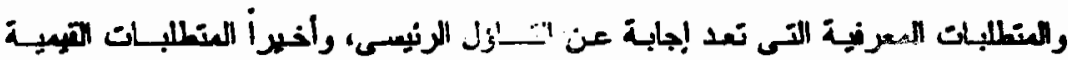

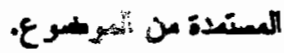

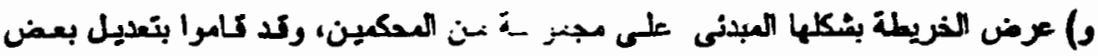

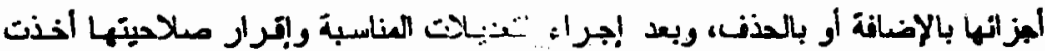

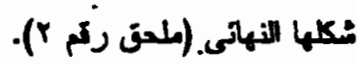

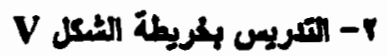

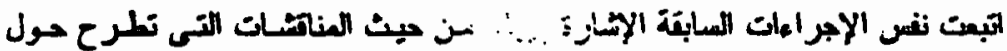

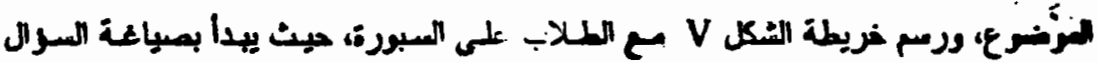

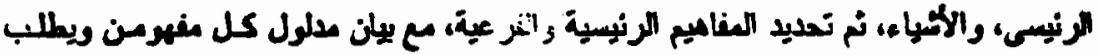

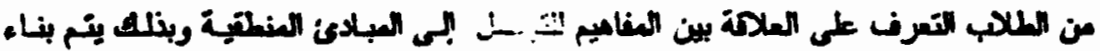

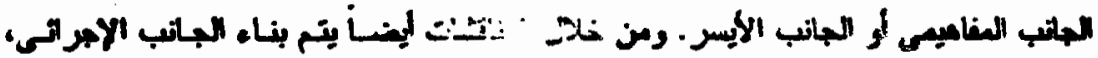

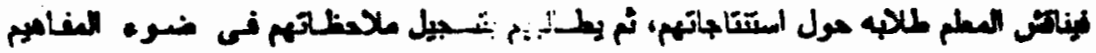




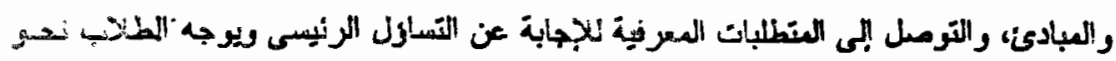

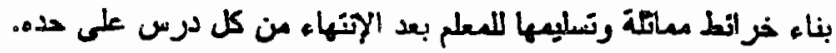

r- التثحيم الذهاتى لكل درس على حده، وللوحدة ككل بعد ذلك.

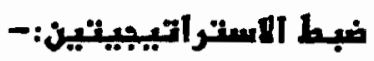

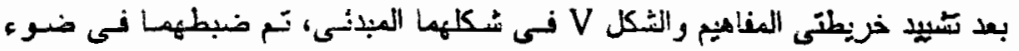

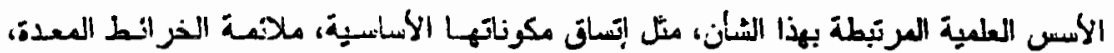

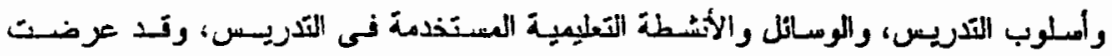

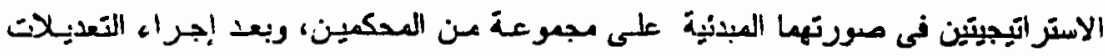

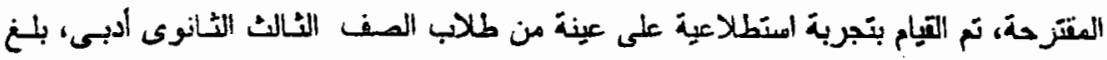

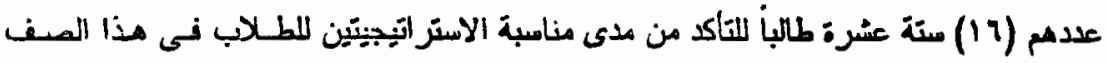
وتذ استجاب الطلاب التعامل مع هذه الخراتط، وتئن مناسبتها لنصائصهم وحاجاتهم مسادة

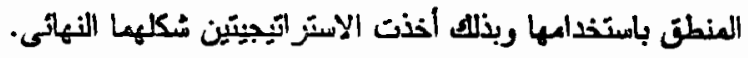

$$
\text { ثانيا: أدوات البحث- الاغتبار التعصيلى:- }
$$

بنى الاغتبار التحسيلى نى موضـوع "المنطق والاستخلال القباسي" وفتى الخطوات

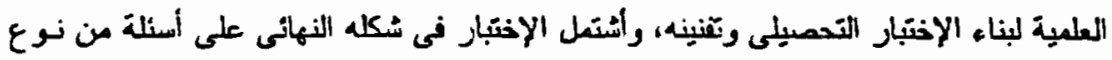

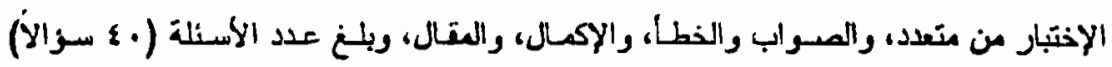

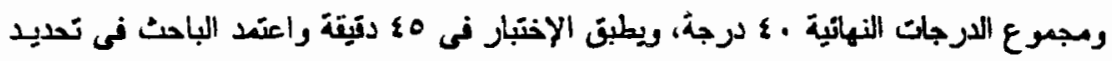

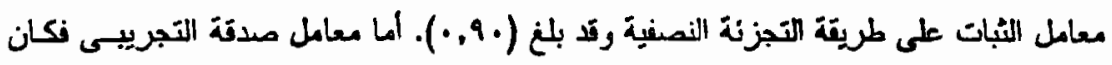
(90, • ) بالاضافة إلى صدت المحكميز، وصدق المحتوى وبذلك أطعنن الباحث إلى أمكانية تطبين هذا الاختبار والوثون بنتائجه.

\section{r- r متياس كتى التحصيل فى العنطق:-}

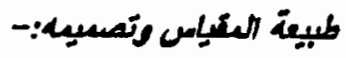

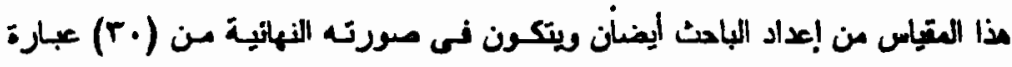

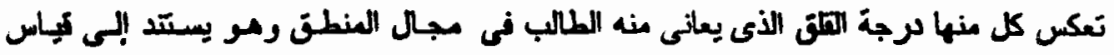

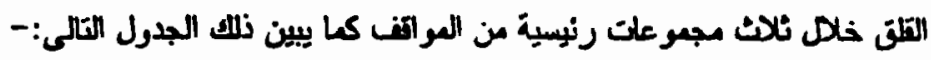




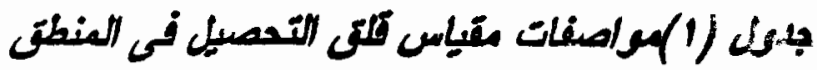

\begin{tabular}{|c|c|}
\hline ارلكام العبارت التى تمثلب & \\
\hline$r_{q}-r_{1}-r_{0}-r_{\varepsilon}-r_{0}-10-1 \varepsilon-10-0-1$ & مواقف تئلت بإتهان المنشتن \\
\hline$r \cdot-r q-r 1-19-1 r-11-9-q-\varepsilon-r$ & 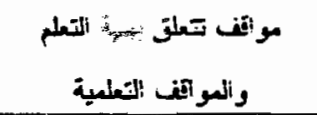 \\
\hline$r q-r r-r r-11-12-17-1 r-n-7-r$ & مواتف تسلت بثخصية المتعلم \\
\hline
\end{tabular}

يتين من الجدول العابئ أن المتياس يتضمن ثلادهة ابعاد رنيستة وهى مواتف نتعلت

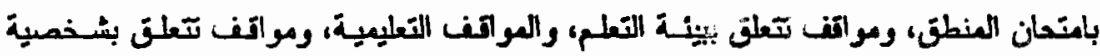

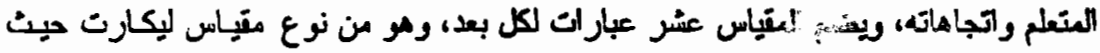

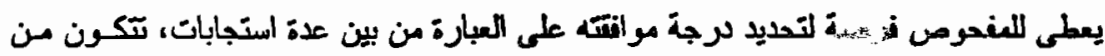

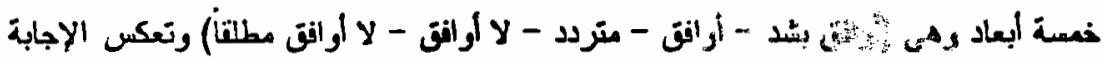

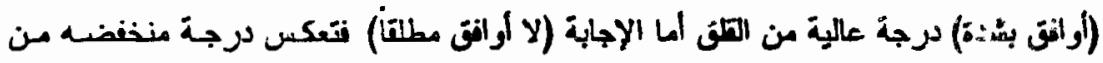

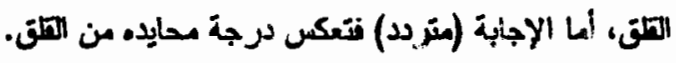

وتد أستعان الباحث بـالعديد من الاختبارت والمتايِس الخاصـة بقلت التحصيـل على

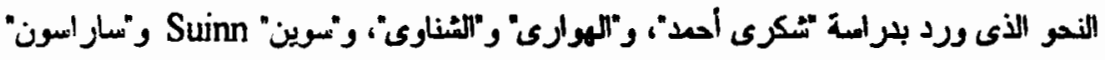
Sarason من التلى فى كل موتف من مجموعات العواقف الثُلاث المبينة بـالجدول (1) وعرضـت

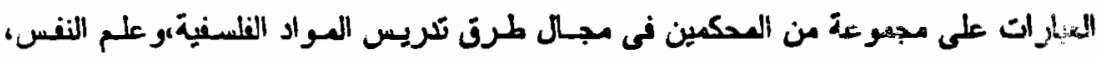
وأنسحة النفسية وتم تعديل مبِاغة بعض العبارات وحذف بعضها الأخر ، وإضافة بعضها فى

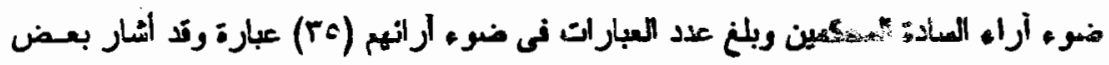

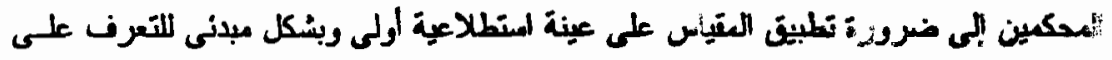

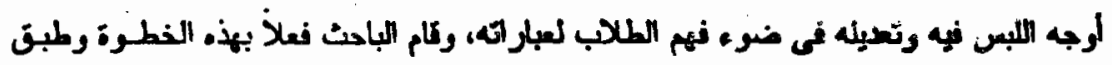




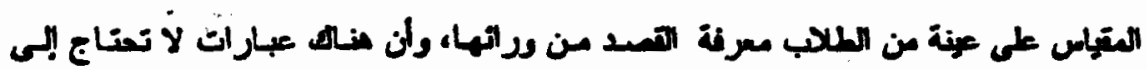

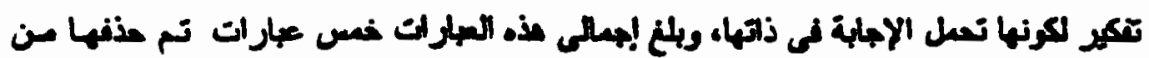

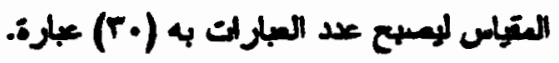

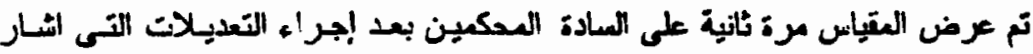

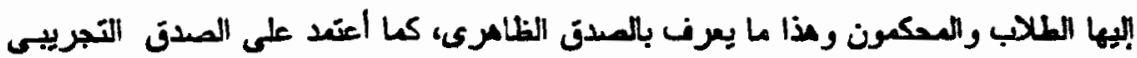
من معامل الثبات وتد بلغ (AA, · ·)، وكذا على صدق المحترى.

ثُبات العتياس:-

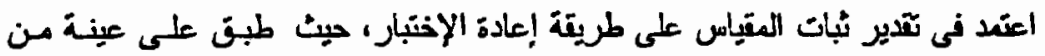

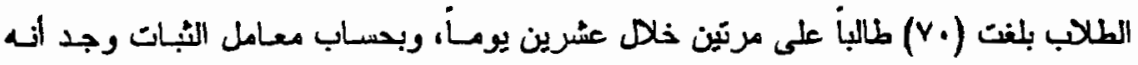

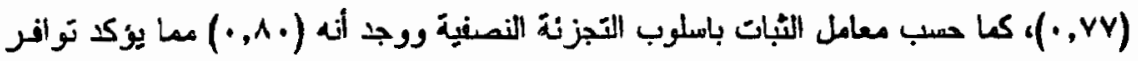
معامل ثبات مثبول للمتياس، وبذلك أذذ المقياس صورته النهائية (ملحن ع).

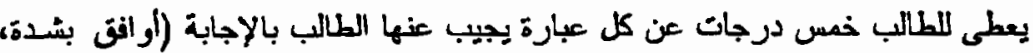
طريتة تصديح المتياس:-

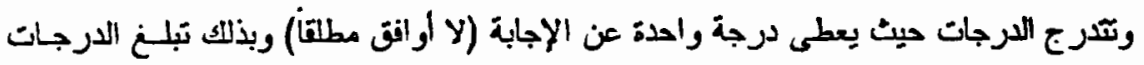

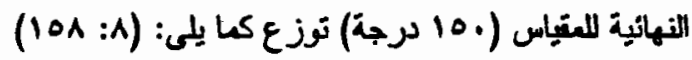

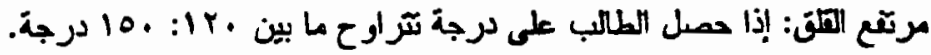

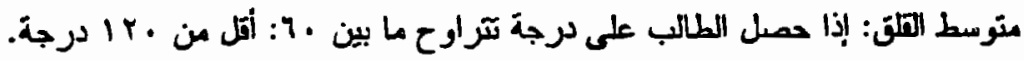

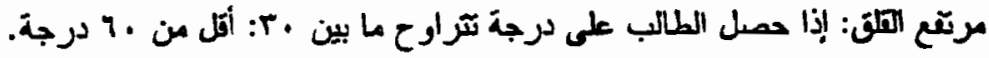

عينة البعث:

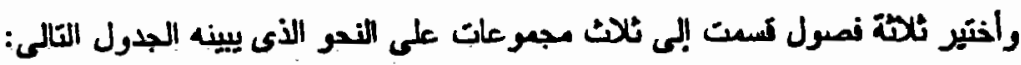




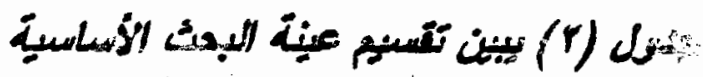

\begin{tabular}{|c|c|c|c|}
\hline لاسترلنينية المتبية & العـدد & hasll & "نعينان \\
\hline خرالنط المغنيم & ro & $1 / 5$ & التجزيتية الأولي \\
\hline خرانط الشكل V & ro & $r / r$ & أنتجربيِة ! \\
\hline الطريقة المعتاذة & To & $\varepsilon / r$ & المضسبطة \\
\hline
\end{tabular}

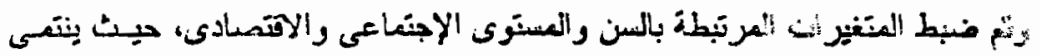

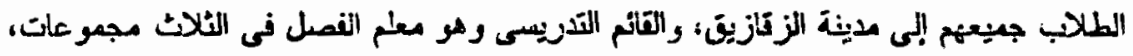

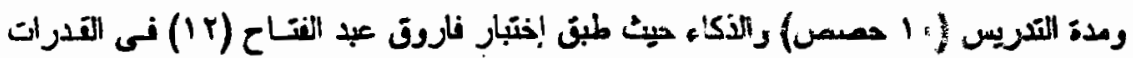

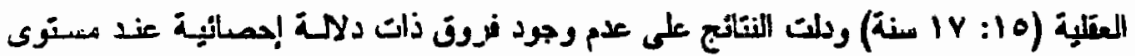

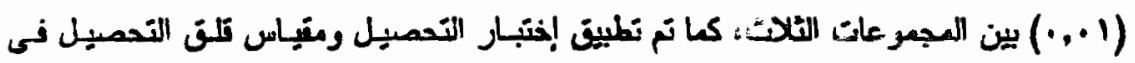

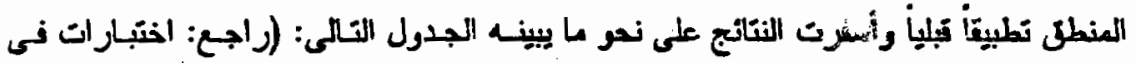

جلول (r) بيين تيع (ت) في التطبيت التبلى لإختبار التحصبل ومعياس

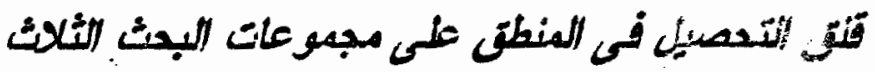

\begin{tabular}{|c|c|c|c|c|}
\hline الضـابطتح & التجريية التحتية & التهريِية الأكلمي & المجيدية & اكتيلير \\
\hline$\cdot$ rA & $0, r o$ & - & التجربة الوكلي & \multirow{3}{*}{ التحصيل } \\
\hline. .08 & - & 0. ro & اللتجريبية الثانية & \\
\hline- &., $0 \leqslant$ & $\therefore, r \wedge$ & المفابطة & \\
\hline.,$r 1$ & .0 & - & التجيبية الأولي & \multirow{3}{*}{ تلن التحصيل } \\
\hline $0,1 \mathrm{Y}$ & - &., 0 & التجرييية القاتية & \\
\hline- &., 18 &.,$r_{1}$ & ibإيl & \\
\hline
\end{tabular}




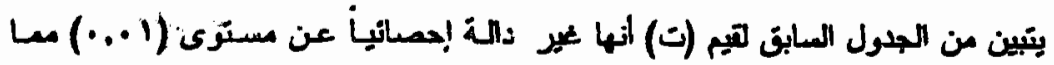

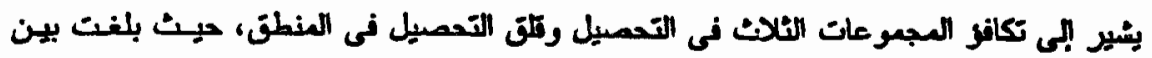

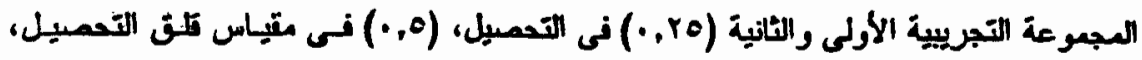
يينا بلغت (rA,

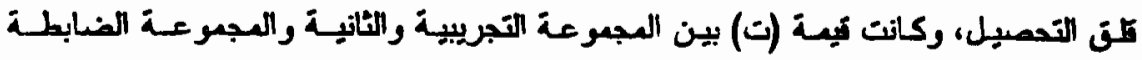

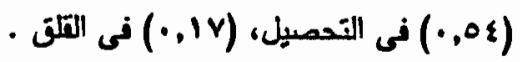

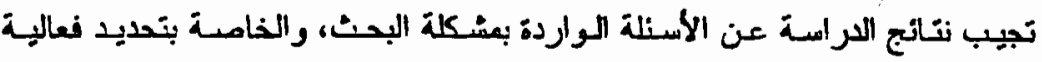

رابعا: نتاتع الاراسة:--

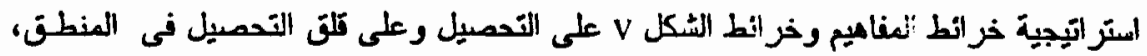

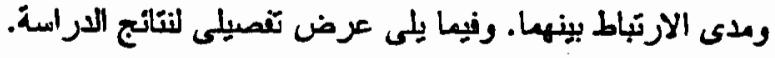

اللرض الأول:

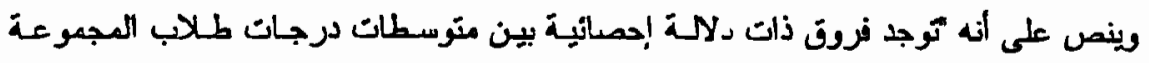

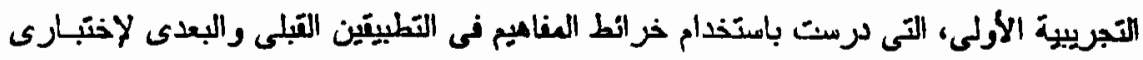

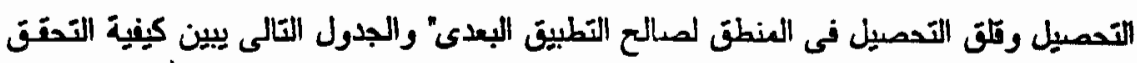
من ذلك:

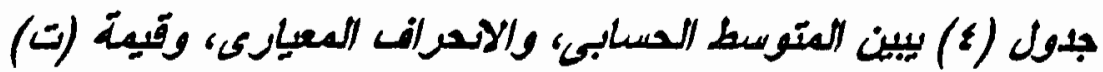

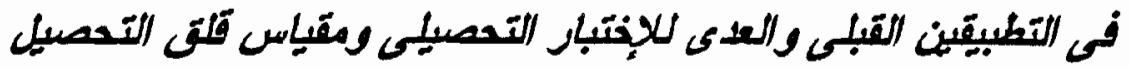

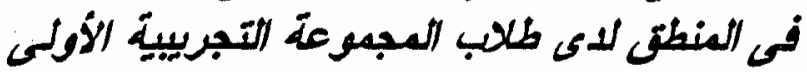

\begin{tabular}{|c|c|c|c|c|c|c|}
\hline الدادة & $ت$ & $\varepsilon$ & $p$ & مج س & التطبيني & الاختبار \\
\hline \multirow{2}{*}{ إستوى } & \multirow{2}{*}{$r v, q r$} & 1,1 & r,OV & 9. & قبلى & \multirow[b]{2}{*}{ التحصيلى } \\
\hline & & $\varepsilon, V r$ & $r e, 1 \mathrm{~V}$ & IrrI & بعدى & \\
\hline \multirow{2}{*}{ 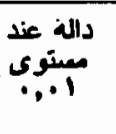 } & \multirow{2}{*}{$\wedge, \wedge r$} & rv,re & $\| v, A$ & $\varepsilon \mid r r$ & تبلي & \multirow[b]{2}{*}{ تلق التحصيل } \\
\hline & & $r r, r)$ & $7 \varepsilon, .9$ & TrET & بعدى & \\
\hline
\end{tabular}

تبين من الجدول السابَن وجود فرون ذات دلالة إجماثية بين التطبيقين القبلى والبعدى

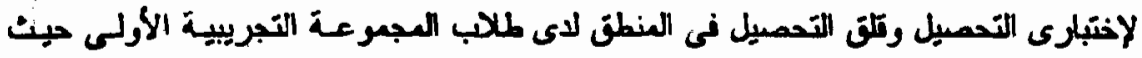




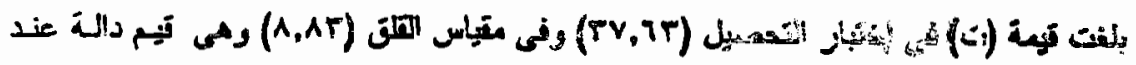

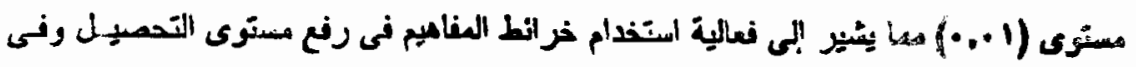

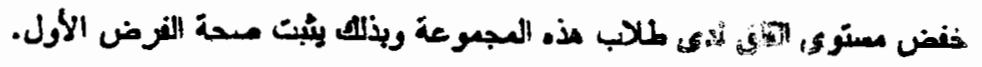

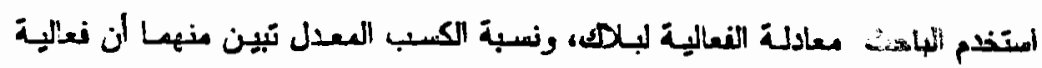

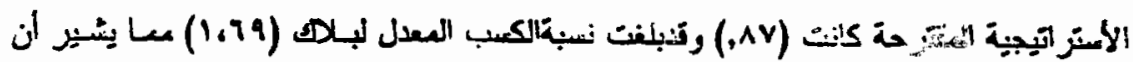

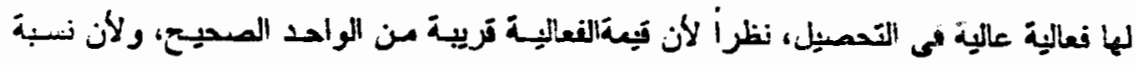

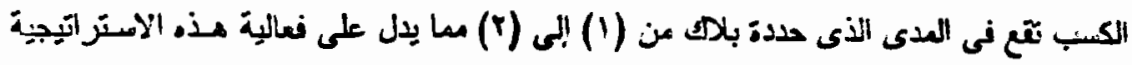

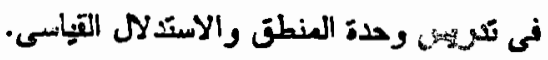

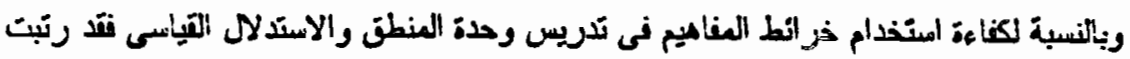

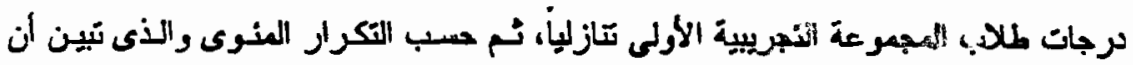

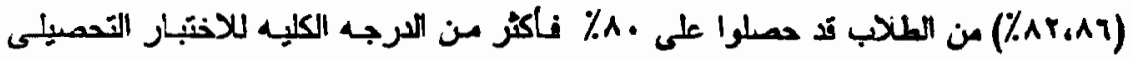

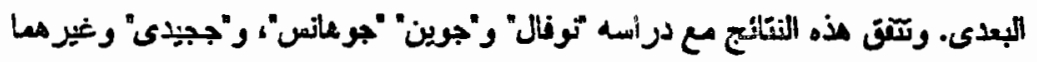

\section{الثرض الثاتى:}

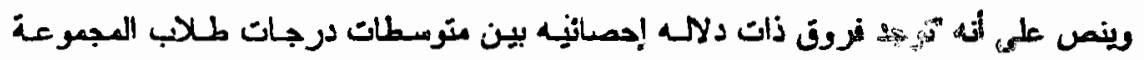

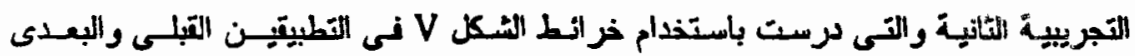

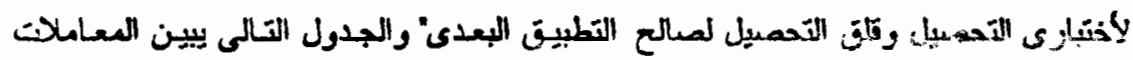
الاحصانية للتحقى من شذا لالنرض.

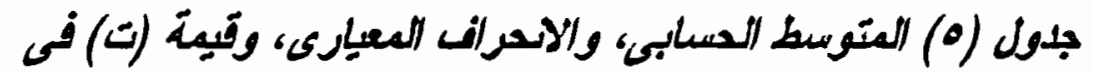

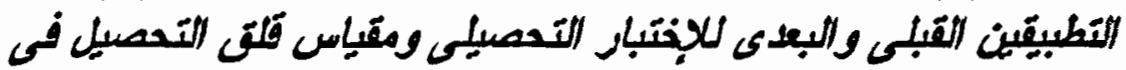
المنطق لدى طلاب المجيموعة التجريبية النآية.

\begin{tabular}{|c|c|c|c|c|c|c|}
\hline الدsi & $ت$ & $\varepsilon$ & $p$ & مج سن & التطبيتي & 1لانتبار \\
\hline \multirow{2}{*}{ 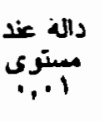 } & \multirow[b]{2}{*}{ TI.1: } & $1, A E T$ & $P, 87$ & 17 & تيلمي. & \multirow[b]{2}{*}{ | } \\
\hline & & 0.19 & $r \varepsilon, 9)$ & ITTY & Eve: & \\
\hline \multirow{2}{*}{ | مالهترى عند } & \multirow[b]{2}{*}{1,71} & rv, ro & 118,7 & $\leq .11$ & $\frac{10}{a}$ & \multirow[b]{2}{*}{ قلق التحسيل } \\
\hline & & $r \cdot, r A$ & A*te! & r.. & بعلك & \\
\hline
\end{tabular}




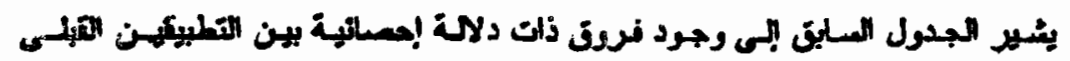

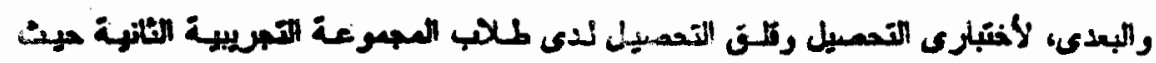

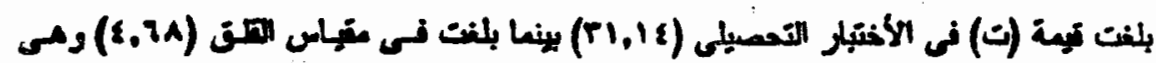

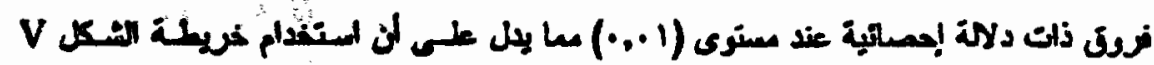

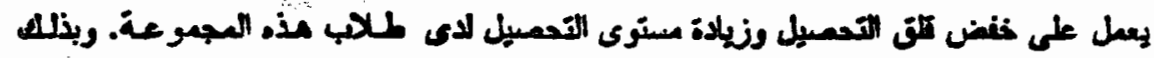

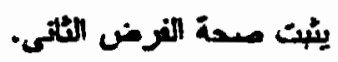

وباستخدام نسبة الفعالية رجد أها (1).A.)، وبحسلب نسبة الكسب السعدل لبله رجد

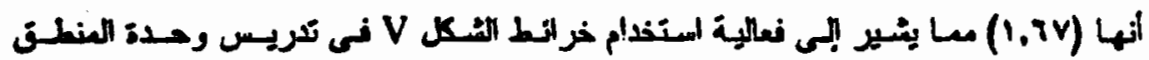

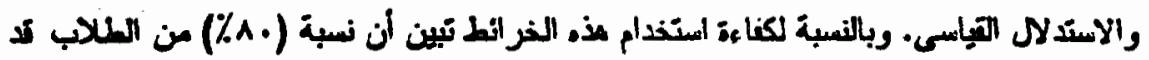

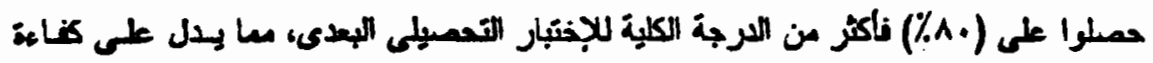

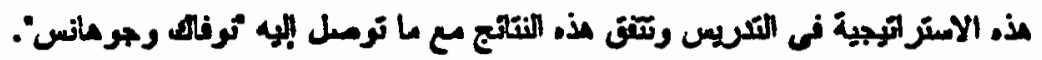

الاعمل الثالث:

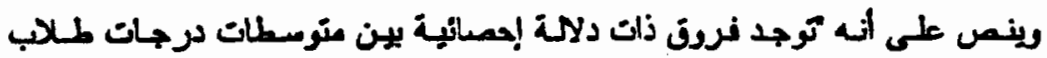

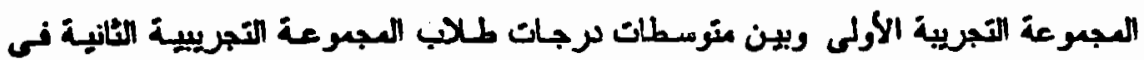

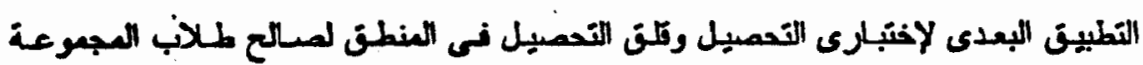
التجرييزة الأولى". والجدول التالى ييين التحتن من نلثك.

-

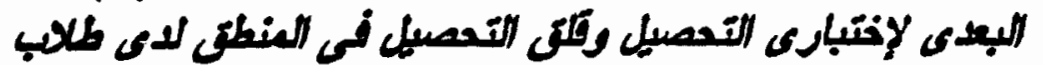
المجيوعتين التجريستين الأولم والثاتية

\begin{tabular}{|c|c|c|c|c|c|c|}
\hline isysy & ت & $\varepsilon$ & $p$ & טب- & strand & saisy \\
\hline \multirow{2}{*}{ مصن } & \multirow[b]{2}{*}{$\cdot r}$. & $8, v r$ & ro,ir & |rr| & التهربة الأرلى & \multirow[b]{2}{*}{ التحصيلى } \\
\hline & & $0, v 9$ & $P\{, 9\}$ & IrrT & التهربة الثطبة & \\
\hline \multirow{2}{*}{ 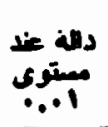 } & \multirow[b]{2}{*}{8.9} & $r Y .71$ & $78,+9$ & YYEY & تاتهربة الأولى & \multirow[b]{2}{*}{ I } \\
\hline & & $r, T A$ & AY,AI & rq. & التهربة المثبة & \\
\hline
\end{tabular}




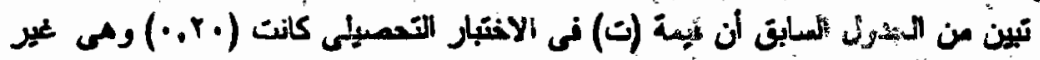

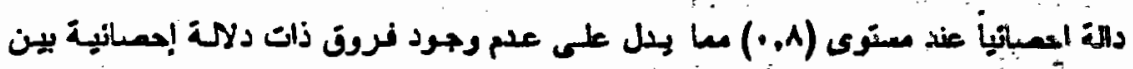

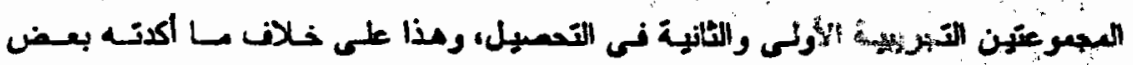

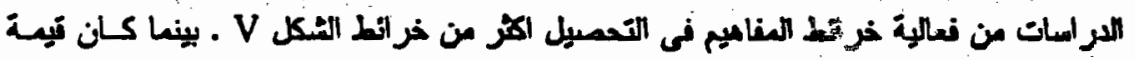

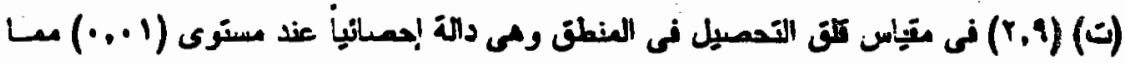

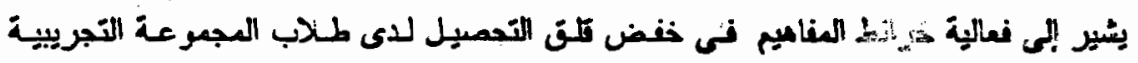

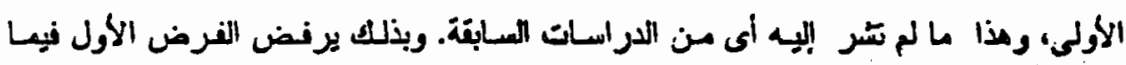

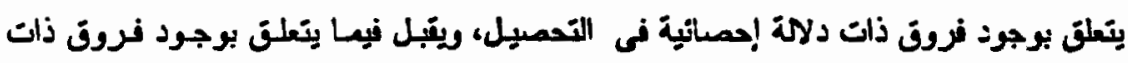

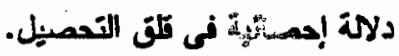

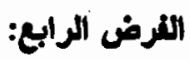

رينص على الثه ترجد نروت ذات دلادة إحمائية يين متوسطات درجات طللاب

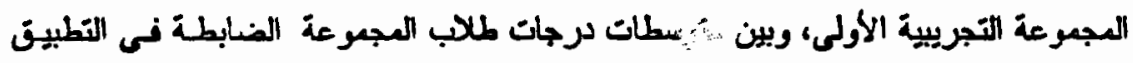

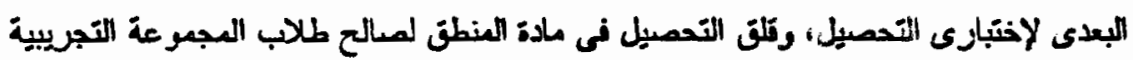

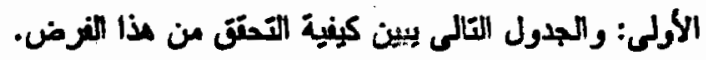

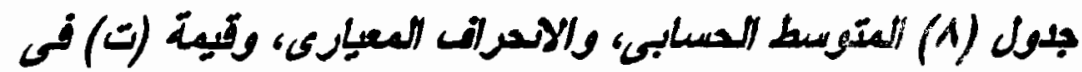

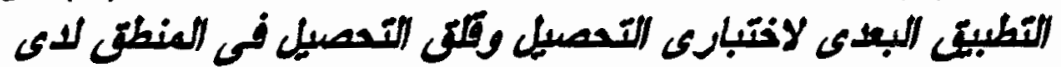

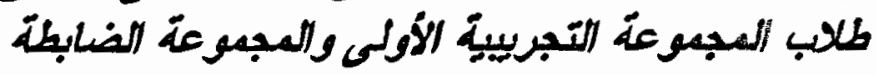

\begin{tabular}{|c|c|c|c|c|c|c|}
\hline IXys & $\Xi$ & $\varepsilon$ & $p$ & مج سن & Iegen: & رint \\
\hline \multirow{2}{*}{ دالمن بندي } & \multirow[b]{2}{*}{8,19} & $£, Y Y$ & ro, I & $|r P|$ & التبربة الأولى & \multirow[b]{2}{*}{ التحمسلى } \\
\hline & & A, 79 & Yr..Y & A. 7 & الشسابطة & \\
\hline \multirow{2}{*}{ دالة عندى } & \multirow[b]{2}{*}{ Y,Aq } & $Y Y, Y I$ & $78 ., 9$ & rYET & التهربة الأرلى & \multirow[b]{2}{*}{ كت لاتعصيل } \\
\hline & & $T ., Y_{7}$ & $110, r$ & $\varepsilon \cdot T Y$ & الهشبطة & \\
\hline
\end{tabular}

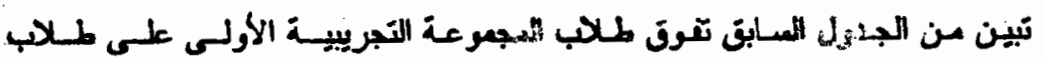

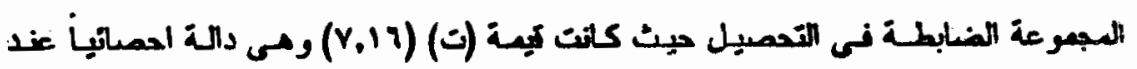

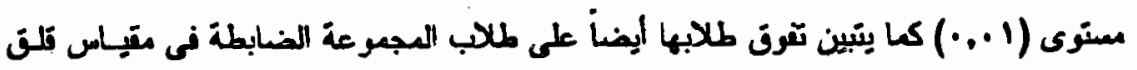




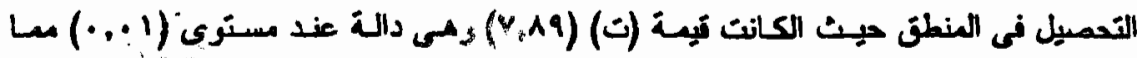

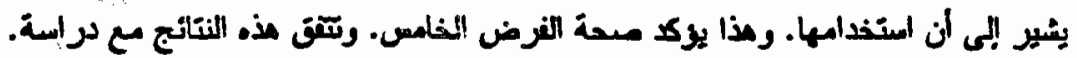

الإن الناسن:

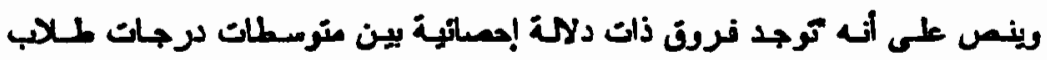

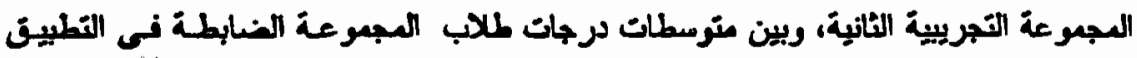

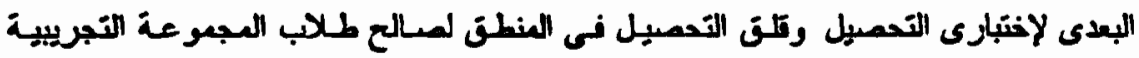

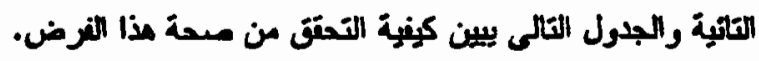

\section{جلول (9) المترسط الحسابع، والأنحراف المعيارى، وقية (ت)}

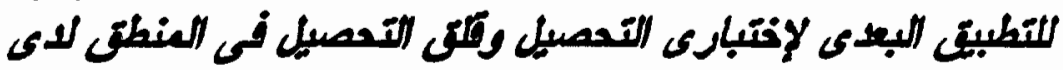

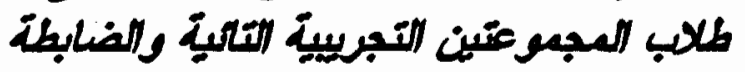

\begin{tabular}{|c|c|c|c|c|c|c|}
\hline II & $\Xi$ & $\varepsilon$ & p & مجس & العبريحت & التخبير \\
\hline \multirow{2}{*}{ دالة عند } & \multirow[b]{2}{*}{$T, \pi$} & 0,19 & $r \varepsilon, 91$ & IIYY & التهربة (V) & \multirow[b]{2}{*}{ التحصيلى } \\
\hline & & 1,79 & $r r, \cdot r$ & A. 7 & آلغابطة & \\
\hline \multirow{2}{*}{ دالث عند } & \multirow[b]{2}{*}{$\varepsilon, \varepsilon$} & $r \cdot, r A$ & AY,QI & rq.r & التهريبة (Y) & \multirow[b]{2}{*}{ تلى التحمسل } \\
\hline & & $r \cdot, Y_{T}$ & $110 . r$ & E.TY & الهابطة & \\
\hline
\end{tabular}

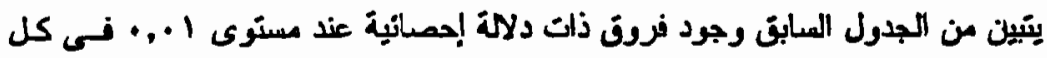

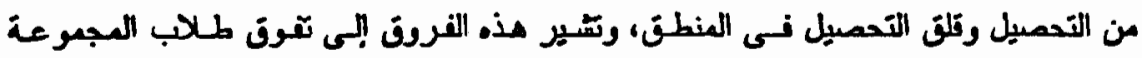

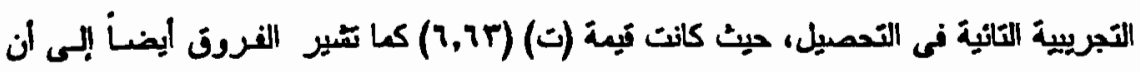

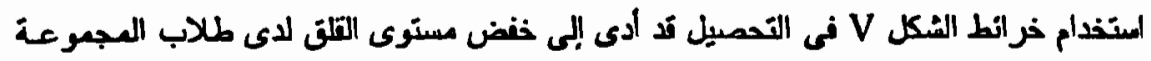

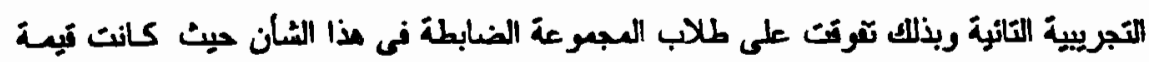

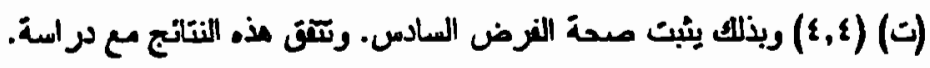

\section{الإض السادس:}

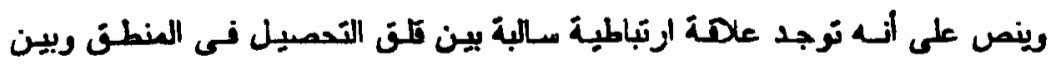

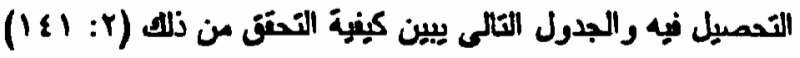




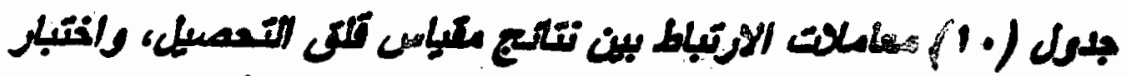

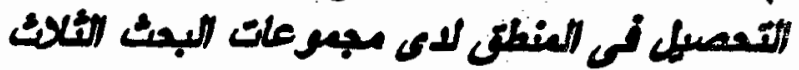

\begin{tabular}{|c|c|c|}
\hline مغتوى الدلانة & معامل الارتهاط بية التمل & iالمبعرعi- \\
\hline دال عند مستوى 1.... &., $7 .-$ & (1) المجمرئة أيريبية \\
\hline دال عند مستوى I..,. & $\cdot, v \varepsilon-$ & السبعوعة التجرييزة (r) \\
\hline دال عند مستوى I.... & $\cdot, x_{1}-$ & العجمرعة الفمابطة \\
\hline
\end{tabular}

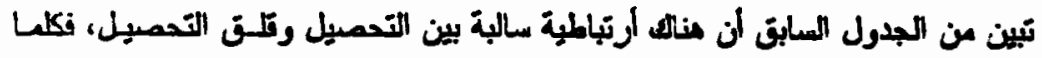

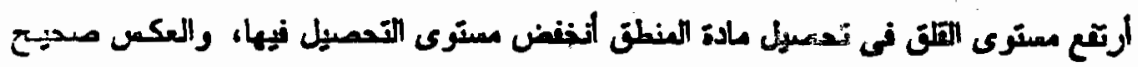

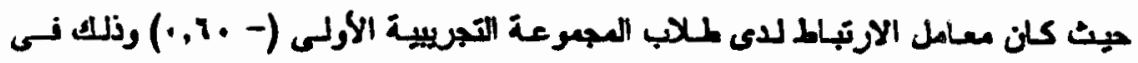

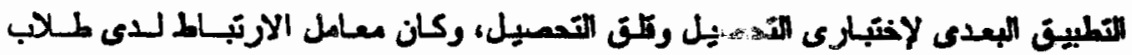

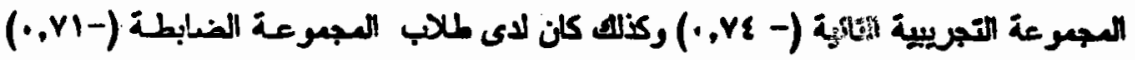

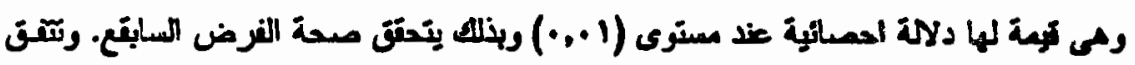

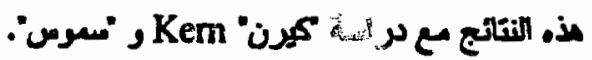

\section{منائشة المتتصع:}

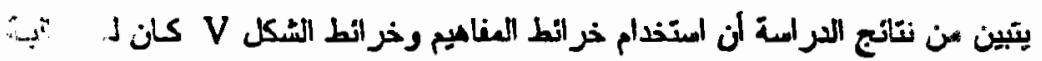

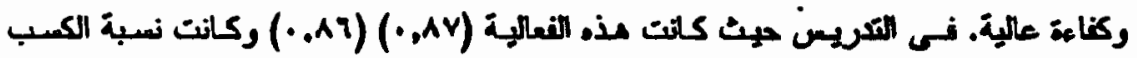

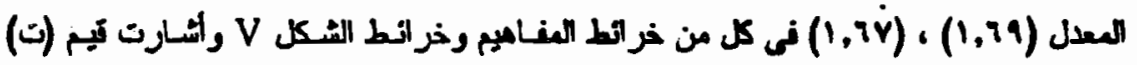

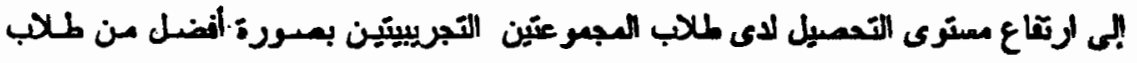

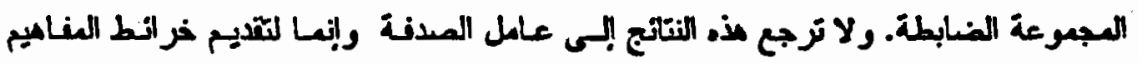

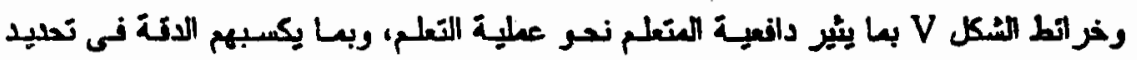

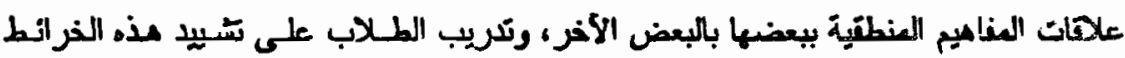

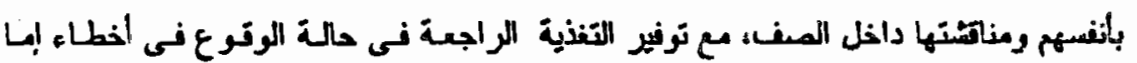

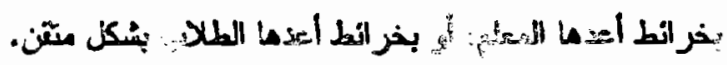

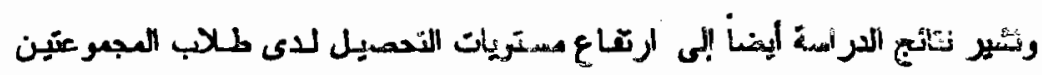

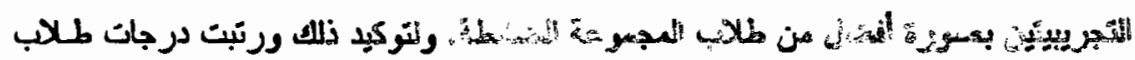




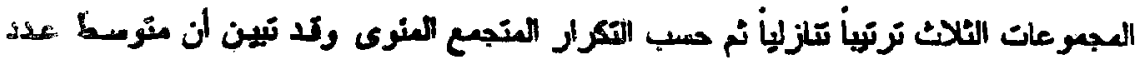

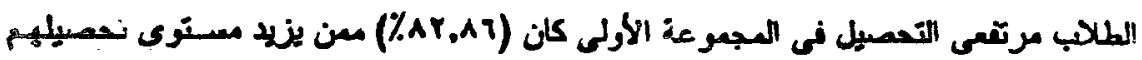

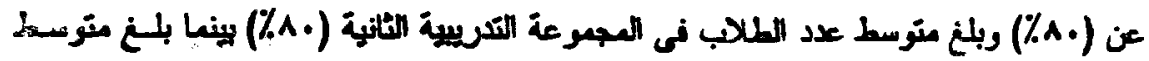

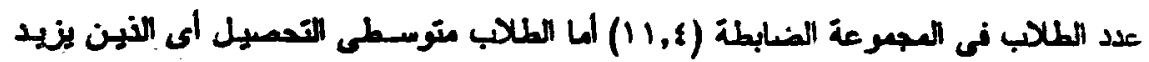

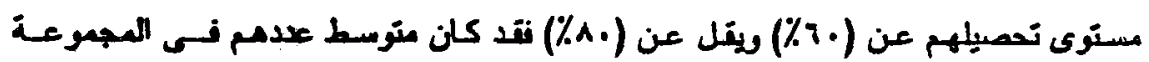

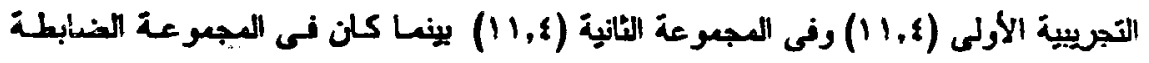

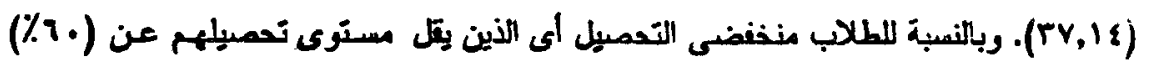

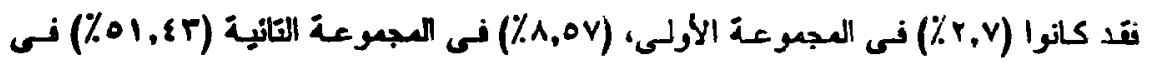

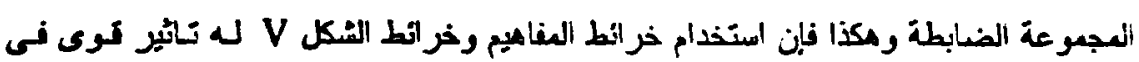

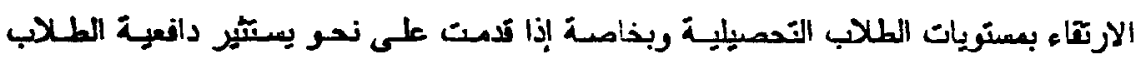
ويجذب انتباههم، ويدفعه نحو عطلية احطم بميث تكرن العادة محبية بالنسبة لهم.

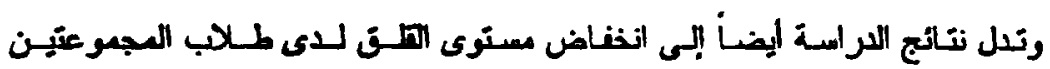

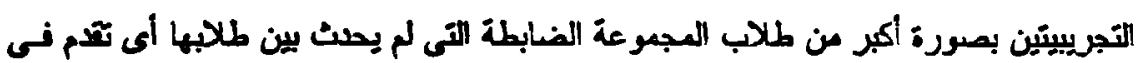

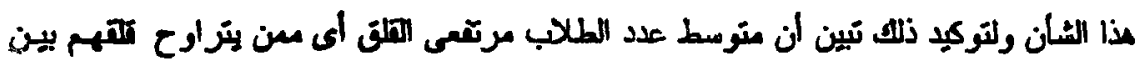

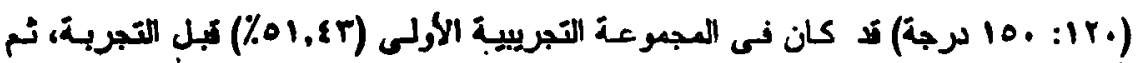

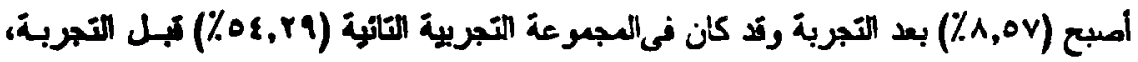

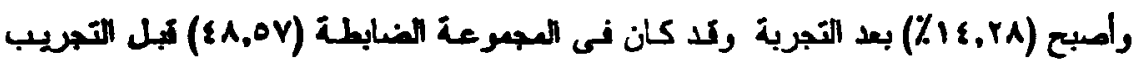

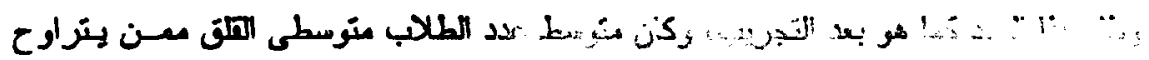

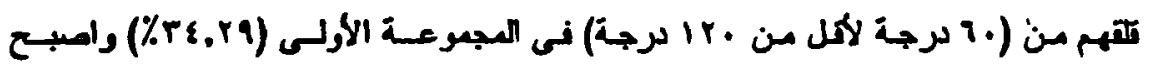
(\&A,OV)

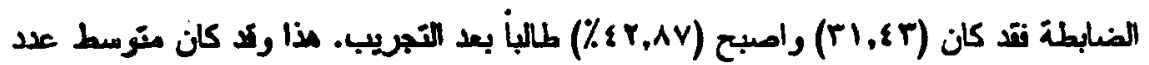

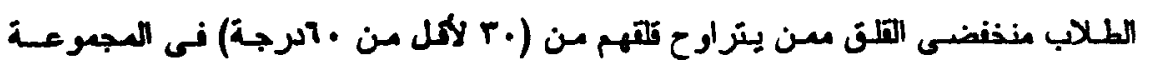

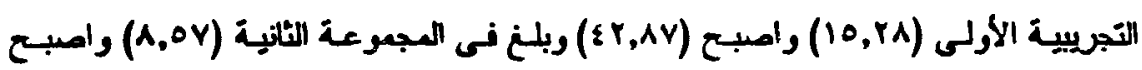

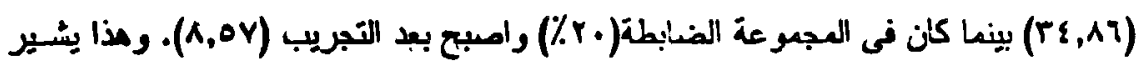

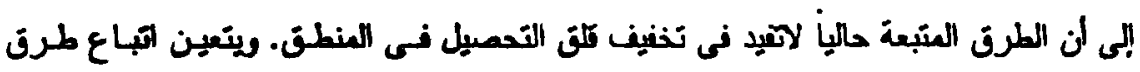

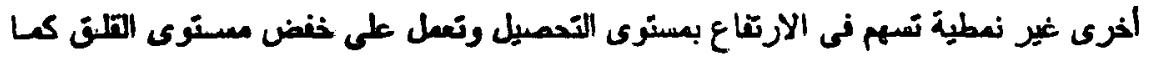

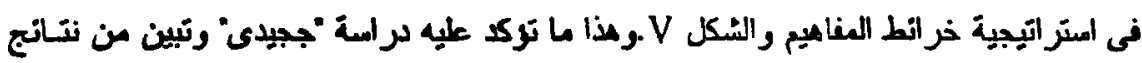

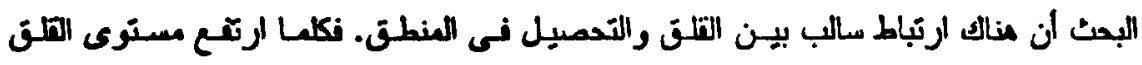

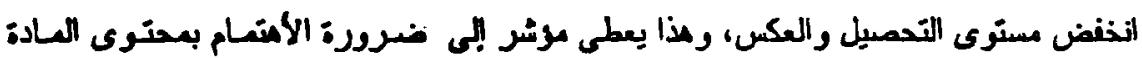




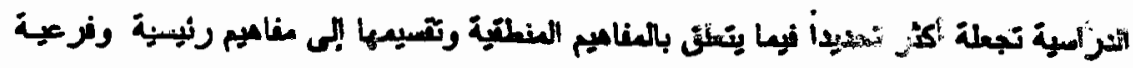

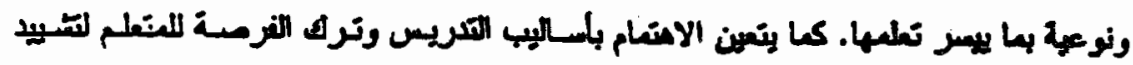

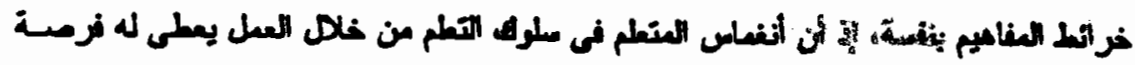

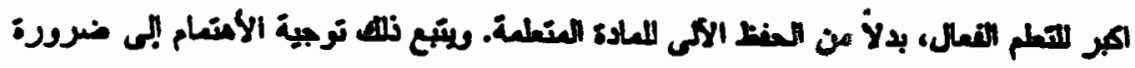

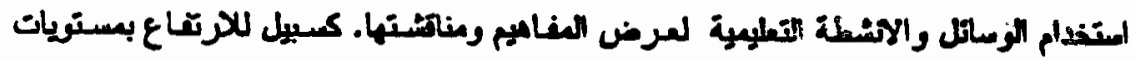

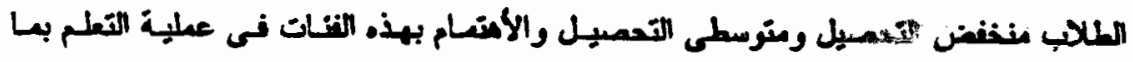

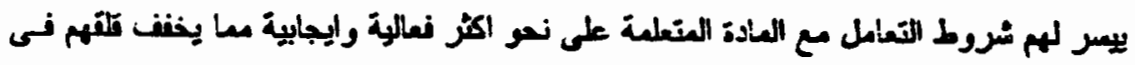
تعصيل مادة العنطق.

\section{التوصبات :}

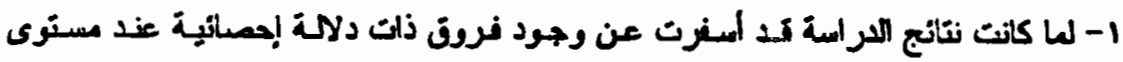

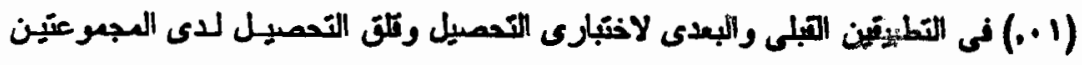

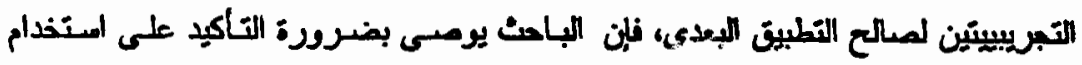

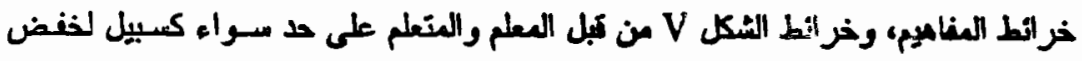

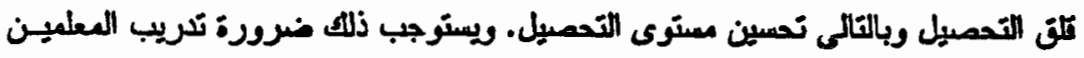

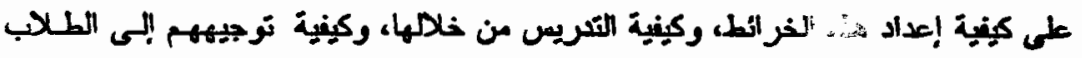

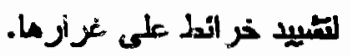

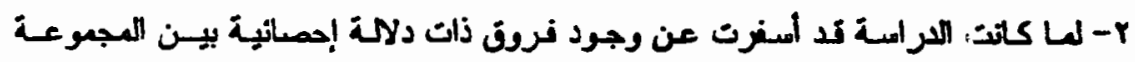

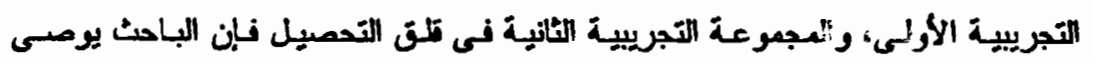

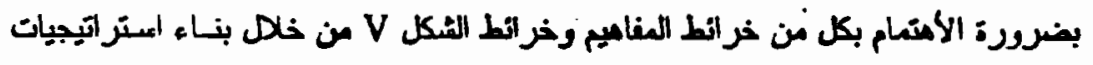

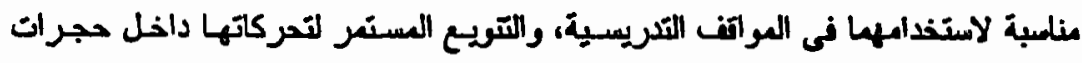
الدراسة بعا لايعل على ملل العتعلم من تطبين استر اتيجية واحدة لألك.

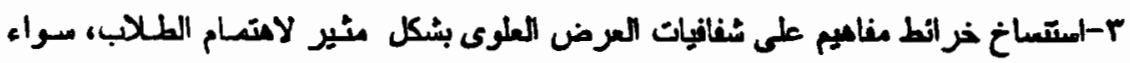

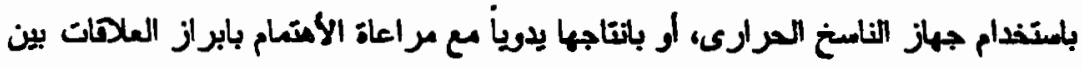
الشفاهيم باستخدام الوان متعددة حتى لاهداخل المغاميم.

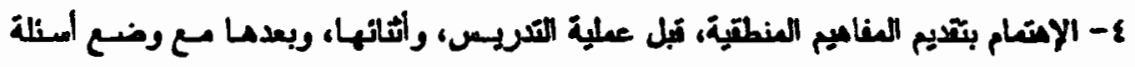

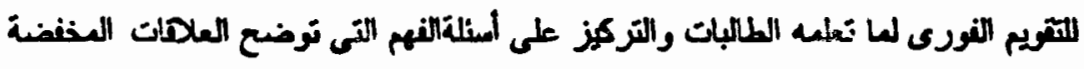
بين المفامبي العنطتبة. 


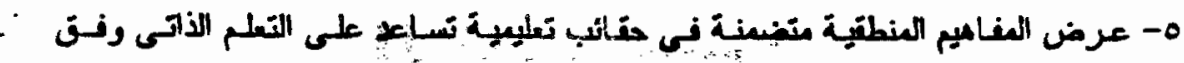

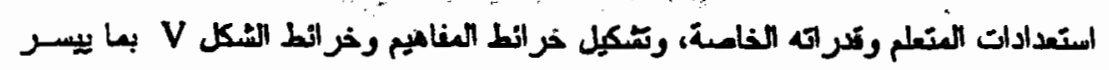

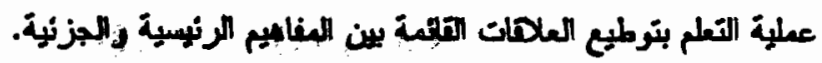

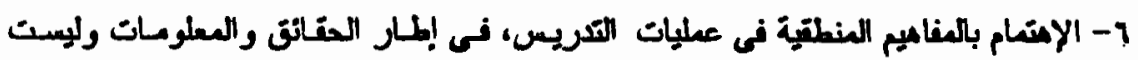

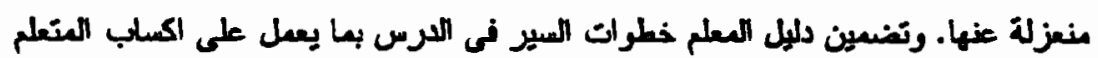
هذه المغامير وفق تسلسلها الهرمى.

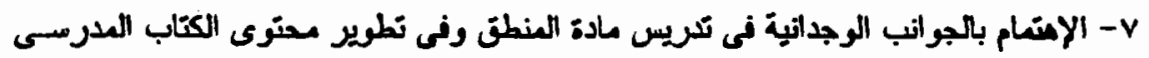
وفق الخمانص النفية لنمو المنعلم.

$$
\begin{aligned}
& \text { السترحات:- } \\
& \text { ليا بليم مترحات بيجمث أفرم فم مجال هذا البهث:- }
\end{aligned}
$$

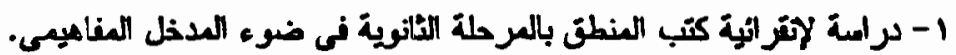

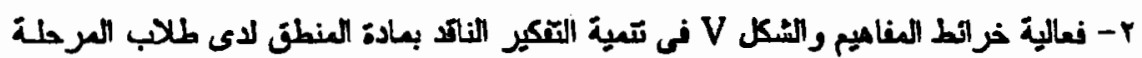
الثانوية.

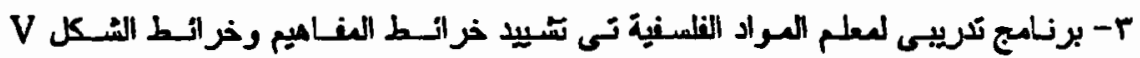
وائز معلى تعمبل العتعلم للعفامير العنطتية.

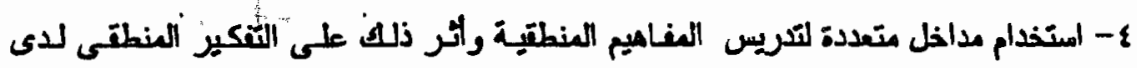
طلاب المرحلة الثانوية. ه- تأثير امتذدام العاب المحاكاة فى اكساب المناميم المنطقية لطلاب الصف الثالث الثانوى الأدبن. 


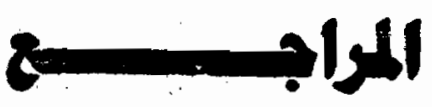

\section{الموالوغ المربية}

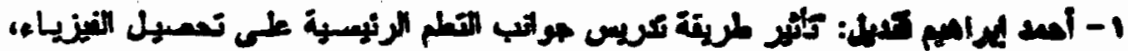

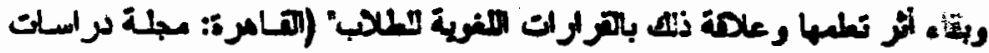

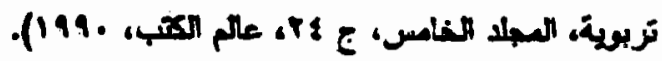

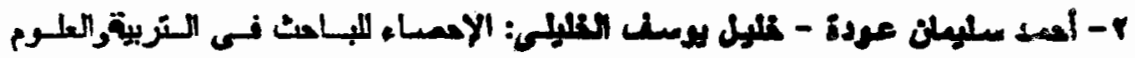

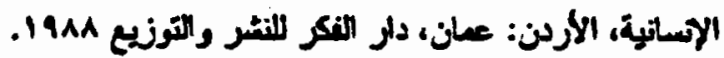

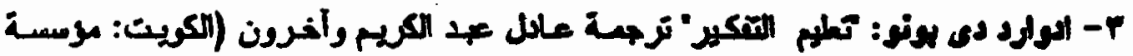

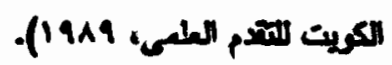

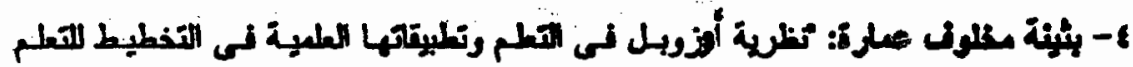

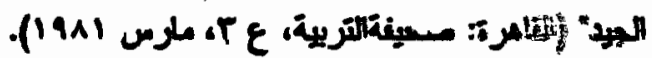

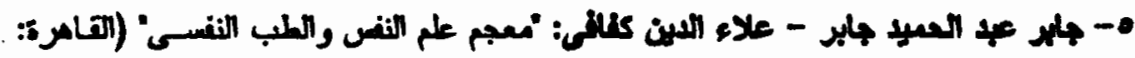

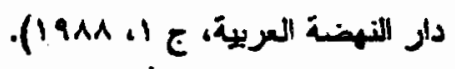

: :معجم علم النفر والطب النفسى" (القامرة، $-1$

دار النهضة العربية، جم م99.

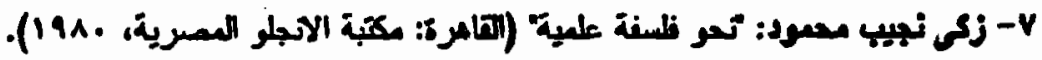

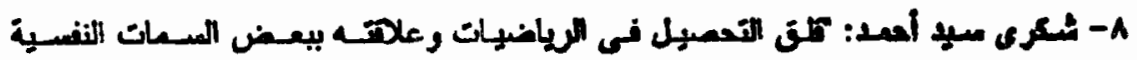

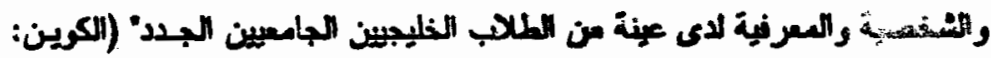

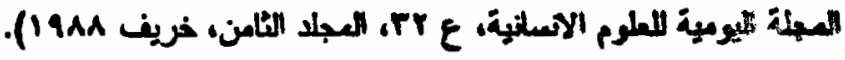




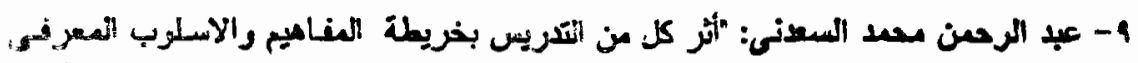

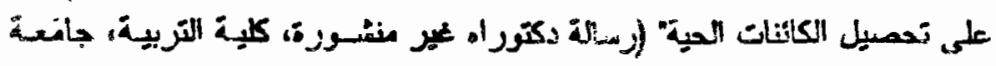
طنطا، 1911.

$$
\text { •- عزمى اسلام: "اسس المنطق الصوزى" (القامرة: الانجلر العصرية، . 19v). }
$$

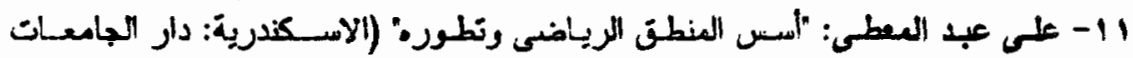

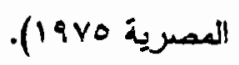

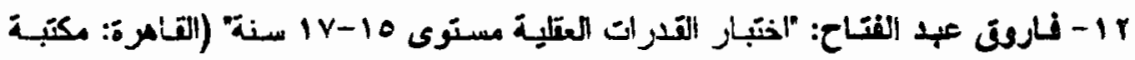

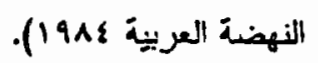

rأ فاطسة معد طلبة: تطرير منهج العراد الفلسفية فى المرحلةالثانوية، فى ضسوء الاتجباه

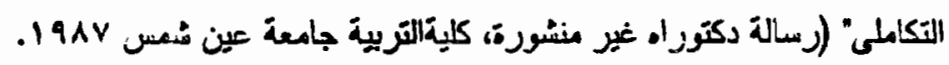

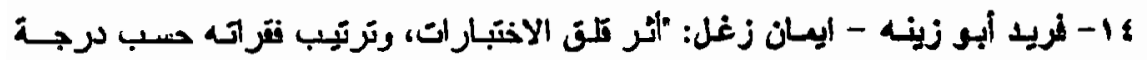

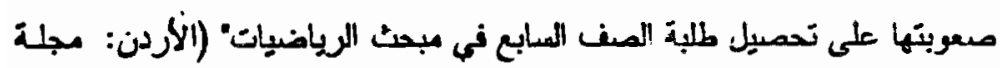

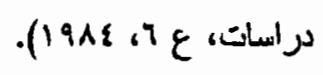

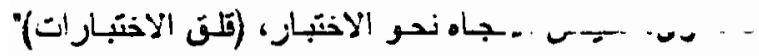

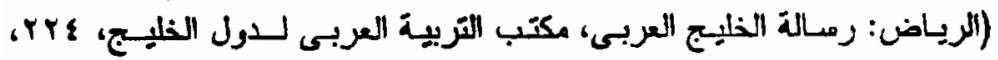
. (19AY

19 - محعود أبو زيد ابراهير: تأثيرِ المنطق الرياضى على تتمية التغكير الناقد نى المرحلة

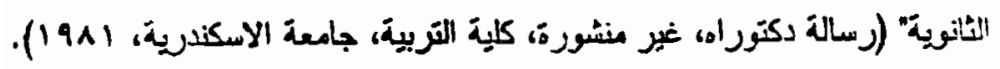

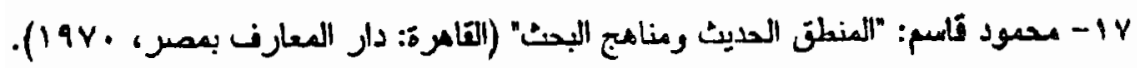
11 - وزارة النعارن العصومية: "منهج التعليم الثانرى" (القاهرة: المطبعة الأميرية، 1491). 
: "منيج التعليم المانوى" (القامرة: المطبعة الأموية، . 19r). $-14$

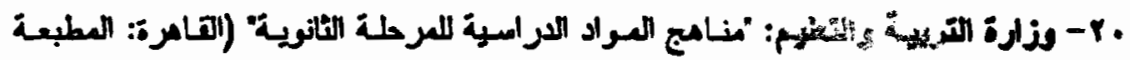

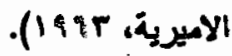

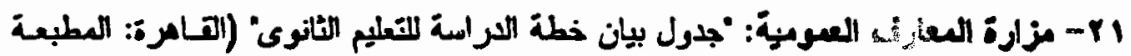
الأعيرية، (19ro)

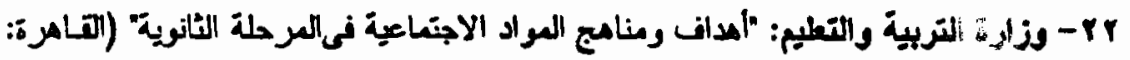

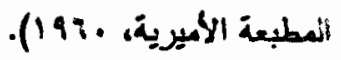

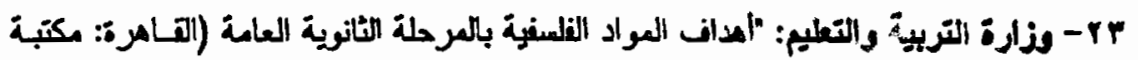

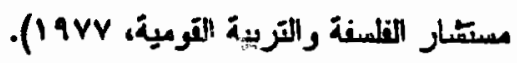

: "العنامج العتدمة للمرطلة الثانوية" (القامرة: العطبعة الاميريـة، $-18$

\section{الهواجع الأونبية}

25- Byrd Pamal Gulley: "Adescriptive study of Mathematics Amxiety its Nature and Antecendents" UnpublishedK Docotral Dissertation, Indiana Univ. 1982.

26- Clut, Pamela S.: Mathematics Anxiety Instructional Method and Achievement in A survey Course in College Mathenatics Journal for Research in Mathematics Education Vol., 15, No. I, 1984. 
27. David C. Munz Abert D. Srionse: Interaction Effects of Iterm. Difficulty Sequnce and Achievement Anxiety Reaction on Academic Performance Journal of Educational Psxchology Vol. 59 , No. $5,1968$.

28- Fryw Elizabeth Wejmer: The Effect of Knowledge of Level of Mathematics Basic Skills on Math Anxiety. Unpublished Doctoral Diss. West Virging University, 1983.

29. Fiedler Y. \& Nachmias R. and Limn M.C.: Leaming Scientific Reasoning Skills In Micro. Computur, Based Laboratories Journal of Research in Science Teaching Vol. 27, No. 2> 1990.

30- Heinze F.J. and Novat J.D.: Concept Mapping Brings Longterm Movement Toward Meaningful Learning. Science Education Vol. 74, No. 4, New: York Johnwiey and Sons Inc. 1990.

31- Howard, Robert W.: Coprante and Snhamatn An In Twad...nti(London Cassel, Educational Kobert W. Howard 1987).

32- Jegede O.J. et al.,: The Effect of Concept Mapping on Students Anxiety and Achievement in Biology Journal of Research in Science Teaching Vol. 27 No. 10., New York Johnwiley and Sons, Inc. 1990.

33- Jhon Collen: Using Concept Maps in Chemistry An Altemative View" Joumal of Research in Science Teaching Vol. 27, No. $10,1990$. 
34- Kern P.D.: A Study of the Relationship Anong Anxiety Self-Esteena and Achievement D.A.I. 4531. A 1970.

Cited in

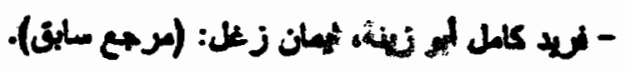

35- Klausmeiev, Herbert, J. and Richard F. Ripple: Leaming and Human Abilities Educational Psychology. Los Angloes, Havper and R on Publishers 3rd ed., 1971.

36- Ling J.L.: A factor - Analytic Study of Mathematics. Anxiety Unpublished Doctoral. Diss. vivginia Polyte Chnic Institute and State University, 1982.

37- Micheal P.W. and Anita R.: The Concept Maps A tool for the Collaborative Construction of Knowledge; A micro-Analysis of High School Physics Students Journal of Research in Science Teaching Vol. 30, No. 5, 1993.

38- Mitchell David: An Introduction to Logic. (London: Hutchinson Co. Ltd. 1968.

39- Moreira Marco: Concept Mapping An Alternative Strategy for Education Assessement and Evaluation in Higher Education Vol. 10. No. 2, Summer 1985.

40- Novak, J.D.: Understanding the Leaming Process and Effectiveness of Teaching Methods in the Classroom Laboratory and Field, Science Education Vol. 6. No. 4, 1976. 
41- Novak J.D.: An Alternative to Piagetion Psxchology for Science and Mathematics Education Science Education Vol. 61, No.4, 1977.

42- Novak J.D.: Concept Mapping: Ausful for Science Education: Journal of R rarch in Science Teaching Vol. 27, No. 10, 1990.

43- Novak J.D. and Gowin D.B.: Learning How to Learn" New York Combridge University Press, 1984.

44- Novak J.D. \& Gowin D.B. and Johansen G.T.: The use of Concept Mapping and Knowledge Vee Mapping with Junior high School Science Students Science Education Vol. 67, No. 5, 1983.

45- Okebukola, Peter Aniksola: Attaining Meaningful Leaming of Concepts in Genetics and Ecology: An Examination of the Potency of the Research in Science Teaching Vol. 27, No. 5, 1990.

46- Okebukola, Peter Aniksola: Attitudes of Teacher Towards Concept Mapping and Vee Pigramming as Metaleaming Tools in Science and Mathematics, Educational Research Vol. 34, No. 3 Winter, 1992.

47- Olybemiro, Teded. and Others: The Effect of Metacognitive Strategy on Students Anxiety and Achievement in Biology. Eric 1989. 
48- Pankratius. W.J.: Buildings an Organized Knowledge Base: Concept Mapping and Achievement in Secondary School Physics, Joumal of Research in Science Teaching Vol. 27, No. 4, 1990.

49- Raymond, Bradly and Norman, S.: Possible World, An Introduction to Logic and its Philosophy Hackett Publishing Co. Inc. 1979.

50- Richardson C. and Woolkolk, F.: Mathematig Anxiety in: Test Anxiety, Theory Research and Applications. Edited Hillsadele N. J., 1980.

51- Soyibo, Kola: Impacts of Concept and Vee Mapping and three Modes - of Class Interaction on Students Performance in Genetics, Educational Research, Vol. 33, No. 2, 1991.

52- Shaughnessy, J. et al.: Relations of Variables of Attitude Toward.Mathematics Vol. 8, No. 3, Jan., 1983.

53- Tylor, Math R.: Changing the Meaning of Experience Empoweving Learning Through the use of Concept Maps; Vee Piagrames and Principles of Education Lab Course. Diss. Abs. Int., Vol. 46, №. 8, 1985. 